\title{
Assimilation of SMOS soil moisture and brightness temperature products into a land surface model
}

\author{
H. Lievens ${ }^{\text {a,* }}$, G.J.M. De Lannoy ${ }^{\text {b }}$, A. Al Bitar ${ }^{c}$, M. Drusch ${ }^{\text {d }}$, G. Dumedah ${ }^{\text {e }}$, H.-J. Hendricks Franssen ${ }^{\text {f }}$, Y.H. Kerr ${ }^{\text {c }}$, \\ S.K. Tomer ${ }^{\text {c }}$, B. Martens ${ }^{\text {a }}$, O. Merlin ${ }^{\text {c }}$, M. Pan ${ }^{\mathrm{g}}$, J.K. Roundy ${ }^{\mathrm{h}}$, H. Vereecken ${ }^{\mathrm{f}}$, J.P. Walker ${ }^{\text {e }}$, E.F. Wood ${ }^{\mathrm{g}}$, \\ N.E.C. Verhoest ${ }^{a}$, V.R.N. Pauwels ${ }^{\mathrm{e}}$ \\ a Laboratory of Hydrology and Water Management, Ghent University, Ghent, Belgium \\ b Global Modeling and Assimilation Office, NASA Goddard Space Flight Center, Greenbelt, MD, USA \\ c Centre d'Etudes Spatiales de la Biosphère, Toulouse, France \\ d European Space Agency, Noordwijk, The Netherlands \\ e Department of Civil Engineering, Monash University, Victoria, Australia \\ ${ }^{\mathrm{f}}$ Agrosphere (IBG-3), Forschungszentrum Jülich, Jülich, Germany \\ ${ }^{g}$ Land Surface Hydrology Group, Princeton University, Princeton, NJ, USA

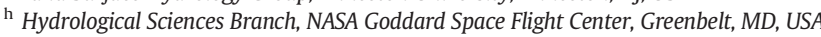

\section{A R T I C L E I N F O}

\section{Article history:}

Received 28 May 2015

Received in revised form 6 October 2015

Accepted 28 October 2015

Available online xxxx

\section{Keywords:}

SMOS

Data assimilation

Soil moisture

Multi-scale

Brightness temperature

\begin{abstract}
A B S T R A C T
The Soil Moisture and Ocean Salinity (SMOS) mission has the potential to improve the predictive skill of land surface models through the assimilation of its observations. Several alternate products can be distinguished: the observed brightness temperature (TB) data at coarse scale, indirect estimates of soil moisture (SM) through the inversion of the coarse-scale TB observations, and fine-scale soil moisture through the a priori downscaling of coarse-scale soil moisture. The SMOS TB products include observations over a large range of incidence angles at both $\mathrm{H}$ - and $\mathrm{V}$-polarizations, which allows the merit of assimilating the full set of multi-angular/polarization observations, as opposed to specific sub-sets of observations, to be assessed. This study investigates the performance of various observation scenarios with respect to soil moisture and streamflow predictions in the Murray Darling Basin. The observations are assimilated into the Variable Infiltration Capacity (VIC) model, coupled to the Community Microwave Emission Modeling (CMEM) platform, using the Ensemble Kalman filter. The assimilation of these various observation products is assessed under similar realistic assimilation settings, without optimization, and validated by comparison of the modeled soil moisture and streamflow to in situ measurements across the basin. The best results are achieved from assimilation of the coarse-scale SM observations. The reduced improvement using downscaled SM is probably due to a lower number of observations, as a result of cloud cover effects on the downscaling method. The assimilation of TB was found to be a promising alternative, which led to improvements in soil moisture prediction approaching those of the coarse-scale SM assimilation.
\end{abstract}

(c) 2015 Elsevier Inc. All rights reserved.

\section{Introduction}

Over land, the Soil Moisture and Ocean Salinity (SMOS) mission has the objective to provide global estimates of surface soil moisture (SM) with a sufficient accuracy and spatio-temporal coverage in order to advance hydro-meteorological science and water management applications. A large number of studies have validated SMOS soil moisture retrievals from regional to global scales (Pan et al., 2012), (Wigneron et al., 2012), (Mecklenburg et al., 2012), (Jackson et al., 2012), (Al Bitar et al., 2012), (Albergel et al., 2012), (Su, Ryu, Young, Western, and Wagner, 2013), (Leroux, Kerr, Richaume, and Fieuzal, 2013), (Leroux et al., 2014), (Rahmoune et al., 2014), (Al-Yaari et al., 2014b),

\footnotetext{
* Corresponding author.

E-mail address: Hans.Lievens@UGent.be (H. Lievens).
}

(Djamai et al., 2015), (Louvet et al., 2015), generally revealing accurate estimates of the near surface soil moisture content. The latter are of particular relevance for understanding the hydrologic cycle, since the near surface soil moisture has a dominant influence on the partitioning of precipitation into infiltration, runoff and evaporation. Consequently, SMOS observations hold a large potential for improving the skill of land surface model (LSM) predictions through data assimilation (DA). The usefulness of SMOS observations for land data assimilation has meanwhile been demonstrated in a number of studies, e.g. (Wanders, Karssenberg, de Roo, de Jong, and Bierkens, 2014), (Ridler, Madsen, Stisen, Bircher, and Fensholt, 2014), (Lievens et al., 2015b) for improved soil moisture and streamflow predictions, and (Martens et al., in press) for improved evaporation estimates.

Despite the previous studies, the assimilation of SMOS observations presents a number of challenges. More specifically, the observations are 
often provided at a coarser spatial resolution than the model grid (Wood et al., 2011), (Sahoo, De Lannoy, Reichle, and Houser, 2013), (Verhoest et al., 2015). Either the DA algorithm will have to account for this spatial mismatch (Reichle, De Lannoy, Forman, Draper, and Liu, 2014), or the satellite products will have to be downscaled a priori (Merlin et al., 2012), (Merlin et al., 2013), (Verhoest et al., 2015). Furthermore, SMOS provides indirect estimates of soil moisture, obtained by the inversion of observed brightness temperatures (TB) through a radiative transfer model (RTM). A direct assimilation of TB observations into an LSM is possible after coupling an RTM as observation operator to the LSM (Balsamo, Mahfouf, Belair, and Deblonde, 2006), (Han et al., 2013), (De Lannoy, Reichle, and Pauwels, 2013), (Reichle et al., 2014), (Han, Hendricks Franssen, Montzka, and Vereecken, 2014), (De Lannoy \& Reichle, in review). Furthermore, the SMOS satellite observes brightness temperatures over a range of incidence angles, both at $\mathrm{H}$ and V-polarization. As such, the TB assimilation can exploit the full set of multi-angular/polarization observations, or may only address a specific sub-set. The potential of the coarse or fine-scale soil moisture, or single or multi-angular/polarization brightness temperature observations, has not been assessed with respect to land data assimilation applications.

The present paper is complementary to (Lievens et al., 2015b), which focuses on the assimilation of a single SMOS observation type, i.e. coarse-scale SM retrievals, with different bias-correction strategies. The objectives of this study are to investigate the potential of assimilating SMOS data, either as downscaled soil moisture, coarse-scale soil moisture retrievals or brightness temperature products, into the Variable Infiltration Capacity (VIC) land surface model (Liang, Lettenmaier, Wood, and Burges, 1994), (Liang, Wood, and Lettenmaier, 1996), (Liang, Wood, and Lettenmaier, 1999), and to provide recommendations on the assimilation strategy to improve hydrologic simulations of soil moisture and streamflow. The merit of the assimilation is studied by comparing the simulations to in situ measurements across the Murray Darling Basin, Australia. Finally, advantages and limitations of the different strategies are discussed, both with respect to technical implementation and performance.

\section{Data and methods}

\subsection{The Murray Darling Basin}

The Murray Darling Basin (Fig. 1) covers an approximate 1 million $\mathrm{km}^{2}$ area in East Australia. The basin holds a large range of climatic conditions, including semi-arid and arid Western Plains, temperate areas in the south-east, subtropical areas in the far north, humid eastern uplands, and alpine country in the Snowy Mountains and Australian Alps, both forming part of the Great Dividing Range. Although the largest portion of the basin is prone to semi-arid conditions, floods occur relatively frequent, often consequent to heavy rainfall events in combination with high antecedent soil moisture conditions. Given its wide range in climatic conditions, the occurrences of floods and droughts, and the availability of an extensive in situ soil moisture and streamflow dataset, the basin offers an excellent case for the validation of LSM simulations.

Soil moisture is monitored in the Murrumbidgee River Catchment, a sub-basin in the south-east of the Murray Darling. The OzNet (Smith et al., 2012) network consists of 62 stations, located mainly in grassland and cropland regions. The stations are equipped with either Campbell Scientific probes measuring over a depth interval of $0-8 \mathrm{~cm}$ or Stevens Hydraprobes measuring over an interval of $0-5 \mathrm{~cm}$. Based on a quality control, 49 stations were selected, for which hourly processed data were available for the years 2010-2011. The data were linearly averaged over the $0.125^{\circ}$ grid adopted by the LSM, resulting in $21 \mathrm{SM}$ validation sites (shown in the inset of Fig. 1). Daily streamflow records
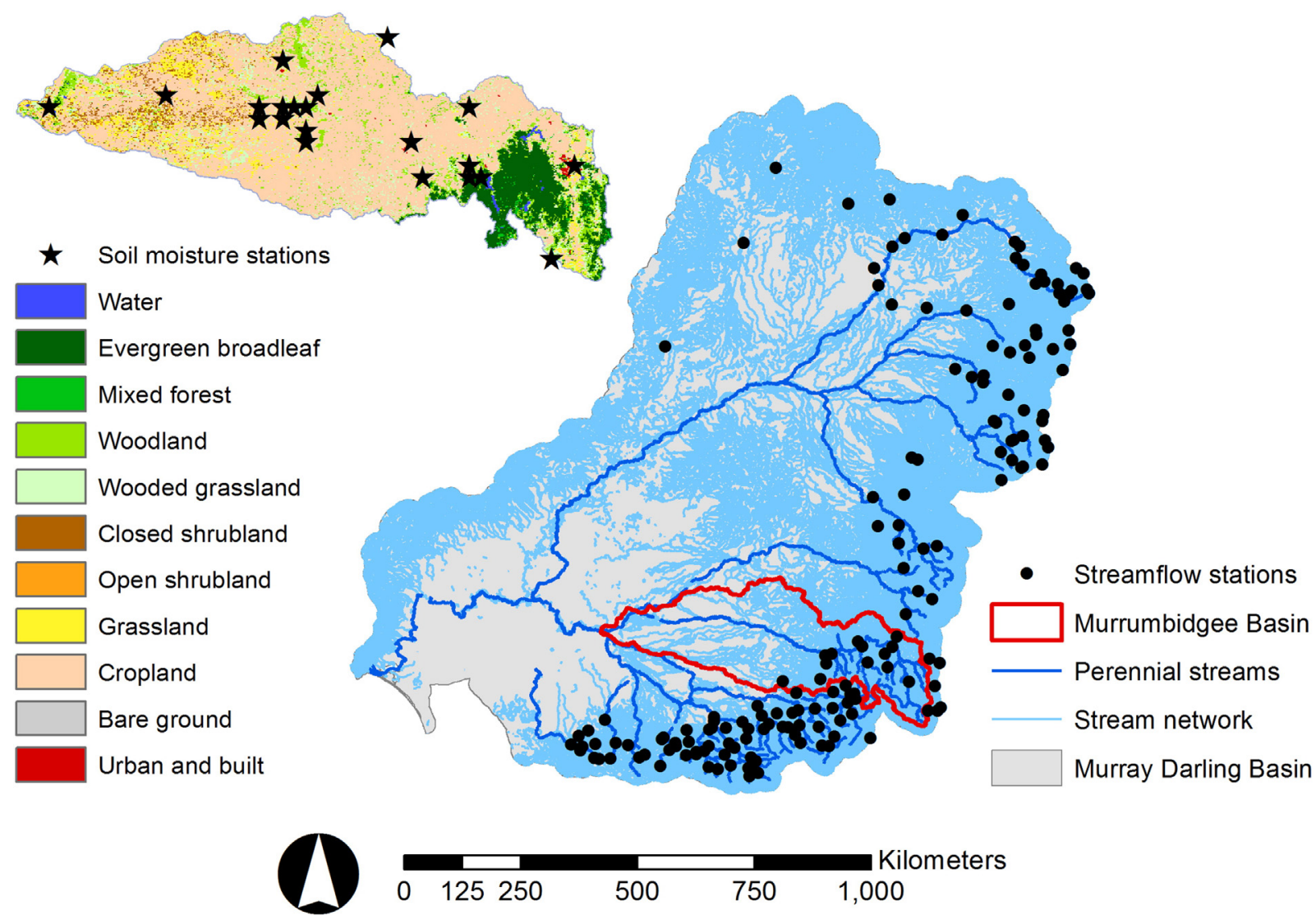

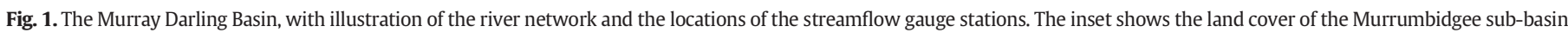
and the locations where soil moisture simulations were validated. 
covering the years 2010-2011 for 169 gauge stations were made available through the Australian Bureau of Meteorology. Only measurements from stations without known dam regulations were used. The stations are mainly located in the Eastern portion of the basin (Fig. 1).

\subsection{SMOS observations}

\subsubsection{Level 3 brightness temperature}

SMOS has been routinely providing global TB observations since 2010 with a repeat period of $\sim 3$ days (Kerr et al., 2012). This study uses the Level 3 CATDS (Centre Aval de Traitement des Données SMOS) brightness temperature product (Jacquette et al., 2010) version 244 . The latter is a global daily product, in which the $\sim 43 \mathrm{~km}$ resolution observations are projected onto a $\sim 25 \mathrm{~km}$ cylindrical EASE (Equal Area Scalable Earth) grid in ground reference ( $\mathrm{H}$ and $\mathrm{V}$ ) frame. The level 3 TB data are multi-angular, comprising angle-bins (per $5^{\circ}$ ) from $17.5^{\circ}$ to $52.5^{\circ}$. The TB data were processed over the Murray Darling Basin from January 1, 2010 to December 31, 2011, i.e. the period for which soil moisture and streamflow validation data are available. As detailed in (Lievens et al., 2015a), the processing included a filtering of the data affected by snow or frozen soil conditions, high $(>0.2)$ radio frequency interference $(\mathrm{RFI})$ probabilities, and significant $(>0.1)$ urban or open water land cover fractions.

To assess the skill of the multi-angular/polarization observation strategy of SMOS in an assimilation framework, three specific TB configurations were tested: (1) observations over 8 angle-bins in the range $17.5^{\circ}-52.5^{\circ}$ at both $\mathrm{H}$ - and $\mathrm{V}$-polarization, (2) a subset of the previous configuration including only observations at $42.5^{\circ}$ in $\mathrm{H}$ - and V-polarization, and (3) a subset with observations at $42.5^{\circ}$ including only H-polarization. These are referred to as TB ${ }_{\Theta, \mathrm{HV}}, \mathrm{TB}_{42.5^{\circ}, \mathrm{HV}}$ and TB ${ }_{42.5^{\circ}, \mathrm{H}}$, respectively.

\subsubsection{Level 3 coarse-scale soil moisture}

Corresponding Level 3 CATDS soil moisture retrievals were also extracted over the years 2010-2011. Similar to the TB data, the soil moisture retrievals were screened for snow and frozen soil conditions, RFI and urban or open water land cover fractions and filtered accordingly. Even though the actual resolution of SMOS is $\sim 43 \mathrm{~km}$, the level 3 CATDS retrievals presented on a $25 \mathrm{~km}$ grid are referred to as the coarse-scale soil moisture $\left(\mathrm{SM}_{\mathrm{c}}\right)$ product for the remainder of this study.

\subsubsection{Level 4 fine-scale soil moisture}

The level 4 fine-scale soil moisture data were produced through the DisPATCh (Disaggregation based on Physical And Theoretical scale Change) downscaling algorithm (Merlin et al., 2012), (Merlin et al., 2013), specifically developed for SMOS. It relies on thermal infrared data collected at medium $(1 \mathrm{~km})$ and high $(<100 \mathrm{~m})$ resolution by MODIS Terra/Aqua and LANDSAT, respectively. The algorithm is based on the reasoning that evaporation can induce a strong coupling of the surface skin temperature with surface soil moisture. Based on a semi-empirical evaporation model, the fine-scale temperature observations can be converted into soil evaporative efficiency, which can subsequently be used for downscaling the SMOS soil moisture through a firstorder Taylor series expansion. The product used in this study (version $\mathrm{sm} 1 \mathrm{k} 3 \mathrm{~d}$ ) is based on 1-km resolution MODIS data collected on 3 consecutive days (centered on the day of the SMOS observation), to estimate the evaporative efficiency. The $1-\mathrm{km}$ soil moisture data were upscaled by linearly averaging over the $0.125^{\circ}$ VIC grid. The screening of the data was performed similarly to that of the coarse-scale soil moisture and brightness temperature data. The fine-scale soil moisture data used for assimilation are further referred to as $\mathrm{SM}_{\mathrm{f}}$.

As the disaggregation is based on infrared remote sensing observations, the algorithm is affected by cloud conditions. When clouds obscure the satellite signal, the downscaling cannot be performed. Consequently, there is a significant number of gaps in the $\mathrm{SM}_{\mathrm{f}}$ product, which may potentially affect the impact of the assimilation due to a reduced number of observations. To assess this impact, an additional observation product was generated in which the coarse-scale $\mathrm{SM}_{\mathrm{C}}$ data have been cross-masked with the $\mathrm{SM}_{\mathrm{f}}$ data. This product is referred to as the $\mathrm{SM}_{\mathrm{c}, \mathrm{m}}$ product. The cross-masking preserved only coarse-scale observations when corresponding downscaled observations were available for more than half of the number of underlying fine-scale grid cells.

\subsection{Model framework}

\subsubsection{Variable Infiltration Capacity model}

The LSM used in this study is the Variable Infiltration Capacity (VIC) model. A detailed description of the model setup and calibration over the Murray Darling Basin can be found in (Lievens et al., 2015b), while a short summary is given here.

VIC is a semi-distributed LSM accounting for both the water and energy balances. The model was implemented to perform hourly simulations of soil moisture, runoff and baseflow at a grid resolution of $0.125^{\circ}$. Each grid cell is statistically subdivided into tiles that represent different land covers. The tiles are composed of a single canopy layer and three soil layers. The canopy layer controls the interception of precipitation as a function of the leaf area index (LAI) according to a biosphere-atmosphere transfer scheme (Dickinson, Henderson-Sellers, Kennedy, and Wilson, 1986). The first two soil layers determine the partitioning of precipitation into surface runoff and infiltration through the variable infiltration capacity curve (Zhao, Zang, Fang, Liu, and Zhang, 1980) and thus capture the dynamic response to the non-intercepted precipitation. The soil moisture from the second layer drains to the third layer as a function of the hydraulic conductivity (Brooks and Corey, 1964), and controls the generation of baseflow via a non-linear recession curve. The first soil layer represents the top $10 \mathrm{~cm}$ of the soil column, whereas the second and third layer have a variable thickness which is typically calibrated. To convert the hourly grid-based simulations of runoff and baseflow to simulations of streamflow at the locations of the gauge stations, VIC was coupled to a simple off-line linear routing model (Lievens et al., 2015b).

The VIC model was calibrated over the Murray Darling region based on streamflow observations over the period 2005-2010. Finally, the model was run for the years 2009 to 2011, where the year 2009 served as a spin-up period. Note that the year 2010 was thus included both in the calibration and validation period. As explained in (Lievens et al., 2015b), this was necessary given that 2010 was considerably wetter compared to the previous years. The Murray Darling basin experienced a Millenium drought with a return to wetter conditions, including significant flood events, in 2010. The inclusion of 2010 in the validation period was found to be necessary since many of the soil moisture and streamflow in situ measurements were only available for the year 2010 and part of 2011.

The meteorological forcing data were taken from the hourly $1 / 2^{\circ}$ latitude by $2 / 3^{\circ}$ longitude MERRA (Modern-Era Retrospective Analysis for Research and Applications) data set (Rienecker et al., 2011). The precipitation field was bias-corrected using the BAWAP (Bureau of Meteorology - Australian Water Availability Project) data set (Jones, Wang, and Fawcett, 2009), which is a gridded assembly of gauge measurements provided at $5 \mathrm{~km}$ resolution. The soil input data, such as texture, bulk density and saturated hydraulic conductivity, were sourced from the $0.1^{\circ}$ Australian Soil Resource Information System (ASRIS) (McKenzie, Jacquier, Maschmedt, Griffin, and Brough, 2012). The land cover data were extracted from the global 1-km University of Maryland (UMD) data set (Hansen, Defries, Townshend, and Sohlberg, 2000), whereas LAI was taken from the 8-day composite MODIS level-4 (MOD15A2) data set with 1-km spatial resolution (Knyazikhin et al., 1999). It is important to mention that the MODIS data were reprocessed to monthly climatological data per land cover tile within each of the $0.125^{\circ}$ grid cells. 


\subsubsection{Community Microwave Emission Modelling platform}

To accommodate the assimilation of brightness temperature observations, VIC was coupled to an RTM. The RTM used modules from the Community Microwave Emission Modelling (CMEM) platform (Holmes, Drusch, Wigneron, and de Jeu, 2008), (Drusch, Holmes, de Rosnay, and Balsamo, 2009), (de Rosnay et al., 2009) version 4.1, which is a general implementation of the $\tau-\omega$ model (Jackson, Schmugge, and Wang, 1982). CMEM was run for each VIC vegetation tile, to simulate the top of atmosphere (TOA) TB at both H- and Vpolarization and incidence angles corresponding to the angle-bins of the SMOS observations, i.e. from $17.5^{\circ}$ through $52.5^{\circ}$ (each $5^{\circ}$ ). The dynamic input to CMEM mainly consisted of the VIC soil moisture (first layer) and soil temperature (skin and third layer). The soil parameters, land cover and LAI used in CMEM were the same as those used for the associated VIC tile. Finally, the simulated TBs at each tile were averaged per VIC grid cell with weights depending on the tile cover fractions within each grid cell.

CMEM has a modular structure, allowing for different parameterization options to model the respective emissivity contributions from the atmosphere, soil, and vegetation. In general, the options selected for this study revert to the L-band Microwave Emission of the Biosphere (L-MEB) formulation by (Wigneron et al., 2007). A detailed description of the module settings used for this study can be found in (Lievens et al., 2015a).

\subsection{Data assimilation framework}

The DA algorithm used the Ensemble Kalman Filter (EnKF, (Evensen, 1994)). The state vector contains the soil moisture content of the two upper layers, the temperature of the skin surface, and the temperature of the three soil layers, for each land cover tile and each VIC grid cell located inside the SMOS grid cell. For each of these land cover tiles the state vector can be written as:

$\hat{\mathbf{x}}_{t, g, k}^{i, f}=\left[\begin{array}{llllll}\theta_{1}^{i} & \theta_{2}^{i} & T_{0}^{i} & T_{1}^{i} & T_{2}^{i} & T_{3}^{i}\end{array}\right]_{t, g, k}^{f}$

In this equation, the . indicates an estimate of the system state. The superscript $i$ is the ensemble member, whereas $f$ stands for the model forecast. The subscript $t$ denotes the tile, $g$ the model grid cell, and $k$ the time step. $\hat{\mathbf{x}}_{t, g, k}^{i, f}$ thus stands for the $i$ th realization of the forecast state vector for tile $t$ and model grid cell $g$ at time step $k$. $\theta_{l}^{i}$ denotes the SM forecast for layer $l$. Similarly, $T_{l}^{i}$ is the temperature forecast for layer $l$, with $l=0$ representing the surface skin. The motivation for including the first and second layer SM in the state vector is that the runoff generation in VIC is a function of the total SM in the first two layers. Inclusion of the second layer is crucial, as it generally dominates the total SM content and consequent runoff fluxes due to its larger layer thickness. The third layer SM was not updated as the SMOS observations do not contain information about this layer, and updating of the layer was found to cause stability problems in the baseflow simulations by VIC.

The collection of state variables within a SMOS observation grid cell area is written as:

$\hat{\mathbf{x}}_{k}^{i, f}=\left[\begin{array}{lllllllllllll}\hat{\mathbf{x}}_{1,1, k}^{i, f} & \hat{\mathbf{x}}_{2,1, k}^{i, f} & \ldots & \hat{\mathbf{x}}_{n_{t}, 1, k}^{i, f} & \hat{\mathbf{x}}_{1,2, k}^{i, f} & \hat{\mathbf{x}}_{2,2, k}^{i, f} & \ldots & \hat{\mathbf{x}}_{n_{t}, 2, k}^{i, f} & \ldots & \hat{\mathbf{x}}_{1, n_{g}, k}^{i, f} & \hat{\mathbf{x}}_{2, n_{g}, k}^{i, f} & \ldots & \hat{\mathbf{x}}_{n_{t}, n_{g}, k}^{i, f}\end{array}\right]^{\mathrm{T}}$,

where $n_{t}$ and $n_{g}$ are the number of land cover tiles within the VIC grid cell and the number of VIC grid cells underlying the SMOS grid cell, respectively. The superscript T stands for the transpose operator.

In the EnKF the state update equation is given by:

$\hat{\mathbf{x}}_{k}^{i, a}=\hat{\mathbf{x}}_{k}^{i, f}+\mathbf{K}_{k}\left[\mathbf{y}_{k}-\hat{\mathbf{y}}_{k}^{i}+\mathbf{v}_{k}^{i}\right]$.
The vector $\hat{\mathbf{x}}_{k}^{i, a}$ contains the analyzed (a) state variables of a single ensemble member $i$. $\mathbf{v}_{k}^{i}$ is a random realization of the observation error, and $\mathbf{K}_{k}$ is the Kalman gain. $\mathbf{y}_{k}$ and $\hat{\mathbf{y}}_{k}^{i}$ are the vectors of observations and observation predictions, respectively. The relationship between the observations and the state variables, commonly referred to as the observation system, is written as:

$\hat{\mathbf{y}}_{k}^{i}=\mathbf{h}_{k}\left(\hat{\mathbf{x}}_{k}^{i, f}\right)$,

where the observation operator $\mathbf{h}_{k}$ maps the state variables onto the observation space.

Three different assimilation strategies were applied in this paper, each with a different observation type. The first and simplest way is the assimilation of downscaled soil moisture products $\left(\mathrm{SM}_{\mathrm{f}}\right)$. This case corresponds with the 1D-F1 filter (De Lannoy et al., 2010), where one fine-scale observation is assimilated per corresponding fine-scale model grid cell. Here, the predicted observation $\hat{\mathbf{y}}$ is the weighted sum of surface soil moisture over all land cover tiles within the model grid cell. The model and observation grids are exactly the same, i.e. $n_{g}$ in Eq. (2) is equal to one. The observation system is in this case a linear operator that can be written as:

$\hat{\mathbf{y}}_{k}^{i}=\left[\begin{array}{lllllll}f_{1} & \mathbf{O}_{5} & f_{2} & \mathbf{O}_{5} & \ldots & f_{n_{t}} & \mathbf{O}_{5}\end{array}\right] \cdot\left[\begin{array}{lllll}\hat{\mathbf{x}}_{1,1, k}^{i, f} & \hat{\mathbf{x}}_{2,1, k}^{i, f} & \ldots & \hat{\mathbf{x}}_{n_{t}, 1, k}^{i, f}\end{array}\right]^{\mathrm{T}}$,

with $f_{t}$ the fraction of land cover tile $t$ within the VIC grid cell, and $\mathbf{O}_{5}$ a vector with five zeros. The zeros in this vector assume that the second layer SM and the temperature profile do not significantly contribute to the simulation of the SMOS observation.

The second strategy is the assimilation of the coarse-scale soil moisture products $\left(\mathrm{SM}_{\mathrm{c}}\right)$. In this case the grid spacing of the observations $(25 \mathrm{~km})$ differs from the model resolution $\left(0.125^{\circ}\right)$, through which a single SMOS grid cell covers multiple VIC grid cells, typically between 2 and 6. This case corresponds with the 3D-C1 filter (De Lannoy et al., 2010), where one coarse-scale observation is used to update the underlying fine-scale model grid cells. Here, the predicted observation $\hat{\mathbf{y}}$ equals the weighted sum of surface soil moisture over all model grid cells within the coarse-scale SMOS grid cell. To account for the fact that model grid cells near the center of the SMOS grid cell contribute more to the observed signal than model grid cells further away from the center, the weighting takes into account the SMOS antenna weighting function. The observation system is linear in this case as well, and can be written as:

$$
\begin{aligned}
\hat{\mathbf{y}}_{k}^{i}= & {\left[\begin{array}{lllllllll}
w_{1} & w_{1} & \ldots & w_{1} & \ldots & w_{n_{g}} & w_{n_{g}} & \ldots & w_{n_{g}}
\end{array}\right] } \\
& {\left[\begin{array}{lllllllll}
\mathbf{F}_{1,1} & \mathbf{F}_{2,1} & \ldots & \mathbf{F}_{n_{t}, 1} & \ldots & \mathbf{F}_{1, n_{g}} & \mathbf{F}_{2, n_{g}} & \ldots & \mathbf{F}_{n_{t}, n_{g}}
\end{array}\right] . } \\
& {\left[\begin{array}{lllllllll}
\hat{\mathbf{x}}_{1,1, k}^{i, f} & \hat{\mathbf{x}}_{2,1, k}^{i, f} & \ldots & \hat{\mathbf{x}}_{n_{t}, 1, k}^{i, f} & \ldots & \hat{\mathbf{x}}_{1, n_{g}, k}^{i, f} & \hat{\mathbf{x}}_{2, n_{g}, k}^{i, f} & \ldots & \hat{\mathbf{x}}_{n_{t}, n_{g}, k}^{i, f}
\end{array}\right]^{\mathrm{T}}, }
\end{aligned}
$$

where $\circ$ is the elementwise (Hadamard) product, and $\mathbf{F}_{t, g}$ the vector with the fractions $f_{t, g}$ of land cover tile $t$ in grid cell $g$ :

$\mathbf{F}_{t, g}=\left[\begin{array}{ll}f_{t, g} & \mathbf{O}_{5}\end{array}\right]$

The weights $w_{g}$ are extracted (and normalized to a sum of 1) from the mean SMOS antenna weighting function (Kerr et al., 2011).

The third assimilation strategy also corresponds with the 3D-C1 filter, but, it uses the coarse-scale brightness temperatures as measured by the satellite, without prior inversion into soil moisture values. The observation vector $\mathbf{y}_{k}$ may comprise the full set of brightness temperatures at incidence angles $\Theta \in\left\{17.5^{\circ}: 5^{\circ}: 52.5^{\circ}\right\}$ and polarizations $p \in\{\mathrm{H}, \mathrm{V}\}$, or a sub-set thereof. To simulate the brightness temperatures, the observation system needs to embed the radiative transfer model 
(CMEM). In this assimilation strategy, the observation system is no longer linear and can be written as:

$$
\begin{aligned}
& \hat{\mathbf{y}}_{k}^{i}=\left[\begin{array}{llll}
w_{1,1, k, 17.5^{\circ}, \mathrm{H}} & w_{2,1, k, 17.5^{\circ}, \mathrm{H}} & \ldots & w_{n_{t}, n_{g}, k, \Theta, p}
\end{array}\right] . \\
& {\left[c\left(\hat{\mathbf{x}}_{1,1, k}^{i, f}, 17.5^{\circ}, \mathrm{H}\right) c\left(\hat{\mathbf{x}}_{2,1, k}^{i, f}, 17.5^{\circ}, \mathrm{H}\right) \quad \ldots c\left(\hat{\mathbf{x}}_{n_{t}, n_{g}, k}^{i, f}, \Theta, p\right)\right]^{\mathrm{T}},}
\end{aligned}
$$

where $c\left(\hat{\mathbf{x}}_{t, g, k}^{i, f}, \Theta, p\right)$ is the RTM applied to the state vector $\hat{\mathbf{x}}_{t, g, k}^{i, f}$ at incidence angle $\Theta$ and polarization $p$. The weights $w_{t, g, k, \Theta, p}$ are based on the area of each tile and the distance from the observation center, as given by the angular-dependent antenna pattern, which is a function of the satellite azimuth and incidence angles, and the footprint axis (Kerr et al., 2011).

The Kalman Gain $\mathbf{K}_{k}$ in Eq. (3) can be calculated based on the ensemble statistics (Reichle, McLaughlin, and Entekhabi, 2002), (Pauwels and De Lannoy, 2009) as:

$\mathbf{K}_{k}=\operatorname{Cov}\left(\hat{\mathbf{x}}_{k}^{f}, \hat{\mathbf{y}}_{k}\right)\left[\operatorname{Cov}\left(\hat{\mathbf{y}}_{k}, \hat{\mathbf{y}}_{k}\right)+\mathbf{R}_{k}\right]^{-1}$

where $\operatorname{Cov}\left(\hat{\mathbf{x}}_{k}^{f}, \hat{\mathbf{y}}_{k}\right)$ is the ensemble error covariance matrix between the state and observation forecasts, $\operatorname{Cov}\left(\hat{\mathbf{y}}_{k}, \hat{\mathbf{y}}_{k}\right)$ is the error covariance matrix between the observation forecasts, and $\mathbf{R}_{k}$ the observation error covariance matrix.

\subsection{Bias correction}

Bias-blind data assimilation requires unbiased observations and forecasts. However, remote sensing observations often reveal a different climatology, i.e. long-term mean and variability, compared to model simulations (Reichle, Koster, Dong, and Berg, 2004), (Verhoest et al., 2015). With regard to SM retrievals, this may be due to the fact that the observations represent a coarser horizontal $(\sim 40 \mathrm{~km})$ and shallower vertical $(<5 \mathrm{~cm})$ spatial extent in comparison to model simulations (Wilker, Drusch, Seuffert, and Simmer, 2006), (Escorihuela, Chanzy, Wigneron, and Kerr, 2010), (Sahoo et al., 2013). For example, the SMOS L3 soil moisture retrievals were found to be systematically drier compared to model simulations of the European Centre for Medium Range Weather Forecasts (ECMWF) Land Data Assimilation System (LDAS) (Al-Yaari et al., 2014a) and MERRA-Land (Al-Yaari et al., 2014b). Climatological differences may become even more pronounced at the TB level (Kornelsen, Cosh, and Coulibaly, 2015), where vegetation and temperature dynamics have a profound impact on the variability from sub-daily over seasonal to inter-annual time-scales. A common practice is to correct for biases prior to the assimilation. Often, corrections are restricted to the first-order moment (the longterm mean), e.g. (Sahoo et al., 2013). Other studies extend to a correction of the second-order moment (the standard deviation), e.g. (Crow, Koster, Reichle, and Sharif, 2005), (Kumar et al., 2012), (Dumedah and Walker, 2014), or to higher-order moments (the distribution) through CDF-matching, e.g. (Reichle and Koster, 2004), (Martens et al., in press). Recently, more comprehensive methods were evaluated, such as the correction of multiplicative biases (Kornelsen and Coulibaly, 2015), biases at the anomaly level or at multi-temporal scales (Su, Ryu, Crow, and Western, 2014), (Su and Ryu, 2015), or triple collocation (Yilmaz and Crow, 2013). Nevertheless, compelling evidence of an optimal method over a large range of conditions is still lacking.

The baseline bias-correction method selected for this study is CDFmatching. The CDF-matching aims at correcting the entire innovation bias, i.e. without distinction between biases in observations and observation predictions. The bias-correction through CDF-matching also averts the assimilation from modifying the climatology of the simulations, and therefore corrects for random errors only. Moreover, it has the potential to work adequately with different observation types. The CDF-matching was performed on a pixel-by-pixel basis using the non- parametric kernel-based method by (Li, Sheffield, and Wood, 2010). Thereby, SMOS observations of SM or TB were rescaled to the distribution of the simulations via their corresponding cumulative probabilities. The data set for the years 2010-2011 was used both for the calculation and matching of the CDFs. The bias-correction and assimilation were restricted to pixels having more than 30 data pairs.

The bias-correction posed specific requirements depending on the observation type to be assimilated. The most simple case is the assimilation of downscaled soil moisture $\left(\mathrm{SM}_{\mathrm{f}}\right)$. In this case, the model and observation grids with $0.125^{\circ}$ resolution match, which facilitates a direct pixel-by-pixel CDF-matching. The coarse-scale $\mathrm{SM}_{\mathrm{c}}$ assimilation required an upscaling of the model simulations to the scale of the observations through the weight vector. Consequently, the bias-correction through CDF-matching is applied at the coarse-scale observation grid. The most complex case regards the TB assimilation, for which the observation operator embeds the RTM. In this case, the TB-bias is minimized a priori through optimizing the forward simulations, as explained in (Lievens et al., 2015a). The bias mitigation for the TB assimilation comprises a first bias-correction step of the VIC SM simulations, i.e. CDFmatching to the SMOS retrievals. This was found to be necessary as (1) the largest part of biases in TB were caused by a different SM climatology between the model and SMOS retrievals, (2) it allows for using RTM parameters that are consistent with those used by the operational SMOS processor, (3) it allows for a realistic assessment of the SMOS TB observation error. In a second step, the RTM parameters were calibrated, as detailed in (Lievens et al., 2015a). Steps 1 and 2 significantly reduce biases at the basin scale, however, regional biases may still be present due to biases in temperature, erroneous soil or vegetation characterization, or shortcomings in the model structure or physics. The third step involves the pixel-based CDF-matching of the SMOS TB observations to the model simulations. Thereby, separate CDFs were calculated for the 8 angular bins, $\mathrm{H}$ - and $\mathrm{V}$-polarizations, and ascending and descending orbits, which may reveal different statistics (Lievens et al., 2015a). It is important to mention that the TB assimilation thus involves two CDF-matching steps: (1) a rescaling of the simulated soil moisture prior to generating TB observation predictions, used in both the Kalman gain and innovation calculation and (2) a rescaling of the observed SMOS TB to ultimately obtain unbiased innovations.

\subsection{The forecast and observation errors}

To characterize the forecast error, an ensemble of model runs was performed, where the number of stochastic realizations was set to 32 (Reichle and Koster, 2003). A detailed description of the ensemble generation is provided in (Lievens et al., 2015b). Consequently, only a brief summary is provided in this paper. The ensemble generation was based on the multiplicative perturbation of model forcings and parameters with random white noise (Turner, Walker, and Oke, 2008). The model forcings being perturbed are precipitation and shortwave radiation. The perturbed model parameters were the bulk density and the exponent of the Brooks-Corey relationship in VIC, and the optical depth $(\tau)$ and scattering albedo $(\omega)$ for tall vegetation types (forests) in CMEM. These parameters have been selected based on sensitivity analyses with VIC and CMEM (data not shown). Furthermore, spatial correlation has been introduced in both the forcing and parameter perturbations. The correlation between adjacent $0.125^{\circ}$-pixels was assumed to be 0.5 , which corresponds with an auto-correlation length of $0.180^{\circ}$ in an exponential correlation function. The introduction of spatially correlated perturbations ensured the generation of coherent forecast errors, which are physically more realistic. The fine-scale SM forecast error standard deviation was characterized by a spatio-temporal average of $0.047 \mathrm{~m}^{3} / \mathrm{m}^{3}$. Relatively larger errors were found in areas subjected to significant precipitation, such as the Australian Alps in the southeast of the basin. The corresponding fine-scale TB forecast error standard deviation was on average $20.0 \mathrm{~K}$ for H-polarization and $14.6 \mathrm{~K}$ for Vpolarization, with higher values over short vegetation caused by the 
larger SM-TB sensitivity. Note that the CMEM parameters $\tau$ and $\omega$ were not perturbed for short vegetation types, given the sufficient spread induced by soil moisture variability.

The observation errors for the different scenarios were specifically tailored to the observation error of the coarse-scale SM data. The observation error standard deviation $\sigma_{R, S M c}$ for the coarse-scale SM assimilation is based on the following model (Lievens et al., 2015b):

$\sigma_{R, \mathrm{SMc}}=a_{\mathrm{SM}}+b_{\mathrm{SM}} \mathrm{DQX}+c_{\mathrm{SM}} \mathrm{FFO}$,

with DQX $\left(\mathrm{m}^{3} / \mathrm{m}^{3}\right)$ the soil moisture retrieval convergence (Kerr et al., 2011), and FFO ( - ) the fraction of the SMOS grid cell covered by forest. The parameters $a_{\mathrm{SM}}=0.02, b_{\mathrm{SM}}=0.5$ and $c_{\mathrm{SM}}=0.02$ specify the contributions of representativeness errors (e.g. due to differences in spatial support), errors of the retrieval model, and errors due to tall vegetation, respectively. For the given set of parameters, the coarse-scale SM observation error ranges from 0.02 to $0.075 \mathrm{~m}^{3} / \mathrm{m}^{3}$, which corresponds well to estimates of retrieval errors in Southeast Australia (Su et al., 2013). For a large number of in situ stations within the Murrumbidgee Basin, error estimates ranged from approximately $0.02 \mathrm{~m}^{3} / \mathrm{m}^{3}$ to $0.1 \mathrm{~m}^{3} / \mathrm{m}^{3}$, with an average of $0.049 \mathrm{~m}^{3} / \mathrm{m}^{3}$ for ascending and $0.043 \mathrm{~m}^{3} / \mathrm{m}^{3}$ for descending orbits.

The coarse-scale observation error $\sigma_{R, S M_{c}}$ was adjusted for the downscaled soil moisture assimilation $\sigma_{R, \mathrm{SM}_{\mathrm{f}}}$ as the error is typically related to the spatial scale of the observations. Assuming no autocorrelation between adjacent pixels, the disaggregation of a coarsescale pixel into $n_{d}$ fine-scale pixels theoretically increases the error as:

$\sigma_{R, S M c}^{2}=\left(\frac{1}{n_{d}}\right)^{2} \Sigma_{i=1}^{n_{d}} \sigma_{R, S \mathrm{M}_{\mathrm{f}, \mathrm{i}}}^{2} \Rightarrow \sigma_{R, \mathrm{SM}_{\mathrm{f}}}=\sqrt{n_{d}} \sigma_{R, \mathrm{SM}_{\mathrm{c}}}$

However, in the case that the surface field shows auto-correlation, the fine scale observation error derived from Eq. (11) will be overestimated. Therefore, a synthetic experiment was carried out to investigate the appropriate rescaling in the case of auto-correlation. In this experiment, an auto-correlated field with a correlation length of $0.180^{\circ}$ (equal to the one assumed in the characterization of the model error) and predefined standard deviation was generated. Subsequently, the field was aggregated over $n_{d}$ pixels, after which the standard deviation was again calculated. As such, the ratio of the fine- and coarse-scale standard deviations can be used instead of the factor $\sqrt{n_{d}}$ in Eq. (11) to rescale the observation error for the downscaled SM with incorporation of spatial error correlation. Table 1 shows these standard deviation ratios for the different levels of disaggregation which occur when downscaling the $25 \mathrm{~km} \mathrm{SMOS} \mathrm{grid} \mathrm{cells} \mathrm{to} \mathrm{the} 0.125^{\circ} \mathrm{VIC}$ grid. For instance, the disaggregation of a SMOS grid cell to 2 by 2 cells $\left(n_{d}=4\right)$ reduces the factor $\sqrt{4}=2$ to a standard deviation ratio of 1.427 when including spatial error correlation.

The observation error for the brightness temperature is theoretically composed of the radiometric error of the instrument and a representativeness error, accounting for errors in the RTM and a different

\section{Table 1}

The $\sqrt{n_{d}}$ and the ratio of the fine-scale $\left(\sigma_{\mathrm{R}, \mathrm{SM}_{\mathrm{r}}}\right)$ over the coarse-scale $\left(\sigma_{\mathrm{R}, \mathrm{SM}}\right)$ observation error standard deviation. These can be used for the calculation of the downscaled SM observation error, when neglecting or accounting for spatial error correlation, respectively. The values are shown for the different levels of spatial disaggregation that occur in this study: $2 \times 1,3 \times 1,2 \times 2$, and $3 \times 2$ cells.

\begin{tabular}{lll}
\hline Disaggregation level & $\sqrt{n_{d}}$ & \\
\hline $2 \times 1$ & 1.414 & $\sigma_{\mathrm{R}, \mathrm{SM}_{\mathrm{r}}} / \sigma_{\mathrm{R}, \mathrm{SM}_{\mathrm{c}}}$ \\
$3 \times 1$ & 1.732 & 1.203 \\
$2 \times 2$ & 2.000 & 1.365 \\
$3 \times 2$ & 2.450 & 1.427 \\
\end{tabular}

representation of the surface fields (De Lannoy \& Reichle, in review). Correspondingly, the observation error was characterized by:

$\sigma_{R, \mathrm{~TB}}=a_{\mathrm{TB}}+b_{\mathrm{TB}}$ Pixel_Radiometric_Accuracy,

where $a_{\mathrm{TB}}(\mathrm{K})$ accounts for the representativeness error and $b_{\mathrm{TB}}(-)$ is a parameter to account for the radiometric accuracy of the SMOS instrument. The value of $b_{\mathrm{TB}}$ was set to 1 in order to comply with the provided radiometric accuracy in the SMOS product, characterized by a spatio-temporal average of $4 \mathrm{~K}$ across incidence angles and polarizations over the basin. The representativeness error $a_{\mathrm{TB}}$ was tailored to the corresponding error in the coarse-scale SM product (Eq. (10)), i.e. $0.02 \mathrm{~m}^{3} / \mathrm{m}^{3}$. As revealed by a sensitivity analysis with CMEM, the error of $0.02 \mathrm{~m}^{3} / \mathrm{m}^{3}$ corresponds to an error of $5 \mathrm{~K}$ for H-polarization, and $3.5 \mathrm{~K}$ for $\mathrm{V}$-polarization, for relatively short vegetation (i.e. LAI of approximately 1) and surface conditions encountered in the Murray Darling Basin. Based on the specified set of parameter values, the spatio-temporal average of the observation error equals $9.0 \mathrm{~K}$ for $\mathrm{H}$ polarization and $7.5 \mathrm{~K}$ for $\mathrm{V}$-polarization. Note that the description of the TB observation error in this study does not take into account the error correlations between observations at different incidence angles and polarizations. Neglecting such correlations might cause stronger peaks in the updates. Hence, the error characterization may still be improved by assessing angular-dependent observation errors, while accounting for their correlations. However, such optimization is outside the scope of this study.

Subsequently, the coarse- and fine-scale SM observation errors and TB observation errors calculated by Eqs. (10) to (12) were rescaled to comply with the bias-correction through CDF-matching. Therefore, the observation error standard deviation $\sigma_{R}^{*}$ is rescaled according to the standard deviations of the simulations $\sigma_{\text {sim }}$ and observations $\sigma_{\text {obs }}$ as follows:

$\sigma_{R}^{*}=\frac{\sigma_{\mathrm{sim}}}{\sigma_{\mathrm{obs}}} \sigma_{R}$

Importantly, it should be remarked that the characterized forecast and observation errors in this study provide only first guess recommendations, which have not been optimized with respect to the performance of the assimilation. A thorough optimization and balancing of the different model and observation errors is beyond the scope of this paper.

\section{Results}

\subsection{Open loop simulations}

Open loop simulations (without data assimilation) in an ensemble mode, with 32 stochastic realizations, were performed for the period 2010-2011. Fig. 2 compares the ensemble mean SM simulations with various SMOS products, in terms of the root mean square difference RMSD and correlation R. The RMSD was generally below $0.05 \mathrm{~m}^{3} / \mathrm{m}^{3}$, except for the center region where differences reached more than $0.1 \mathrm{~m}^{3} / \mathrm{m}^{3}$. This larger error was caused by the model being significantly drier than the observations for the period from March to June 2011. However, no specific reasons for this anomaly could be identified. Overall, similar RMSD values were obtained at the fine and coarse scale. In contrast, the correlation was generally lower at the fine scale, particularly in the southern portion of the basin. The reason therefore may be twofold: (1) the analysis at coarser scale may have smoothed out part of the errors through which a better correspondence was obtained, and (2) the number of data points (in particular during wet conditions) was lower for the fine-scale product as downscaling was omitted during cloud cover and precipitation. The latter is evidenced by the crossmasked $\left(\mathrm{SM}_{\mathrm{c}, \mathrm{m}}\right)$ data set, which revealed a similar reduction in $\mathrm{R}$ compared to $\mathrm{SM}_{\mathrm{f}}$. 
$\operatorname{RMSD}\left(\mathrm{m}^{3} / \mathrm{m}^{3}\right)$

$\mathrm{SM}_{\mathrm{C}}$

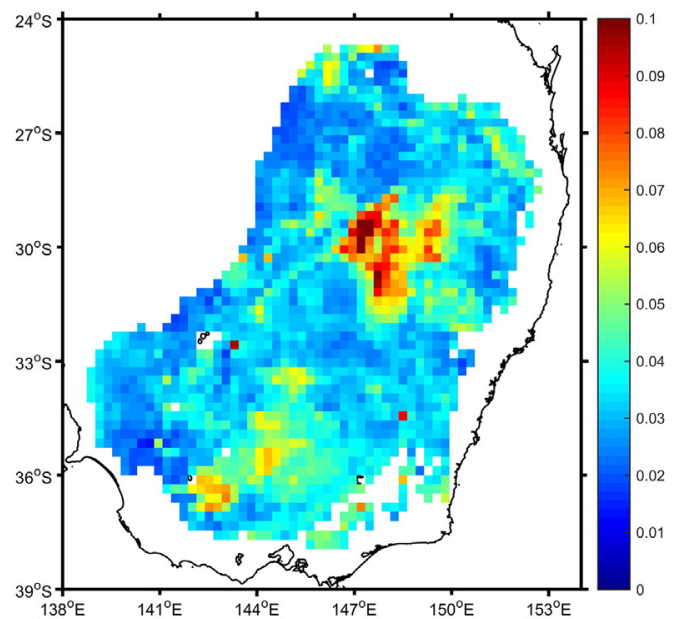

$\mathrm{SM}_{\mathrm{c}, \mathrm{m}}$

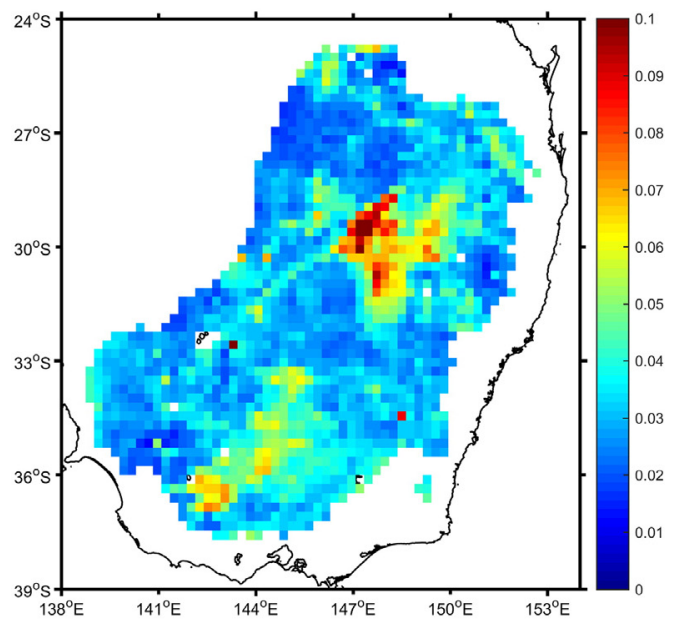

$\mathrm{SM}_{\mathrm{f}}$

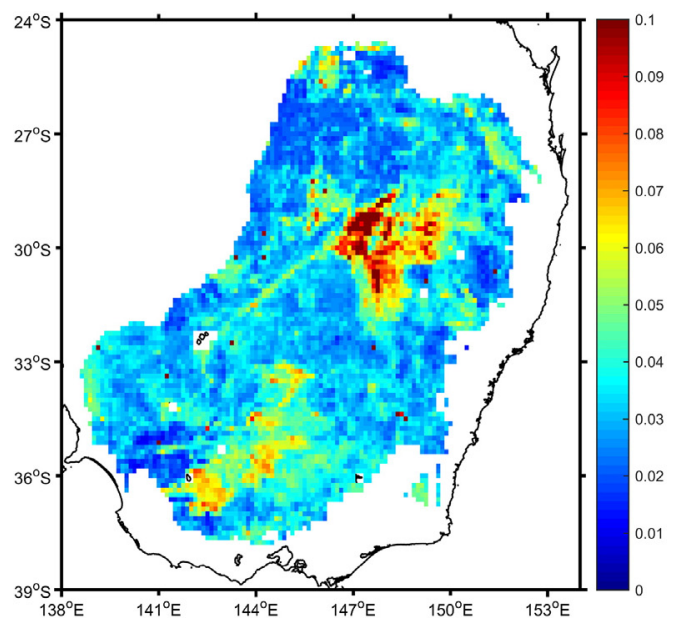

$\mathrm{R}(-)$
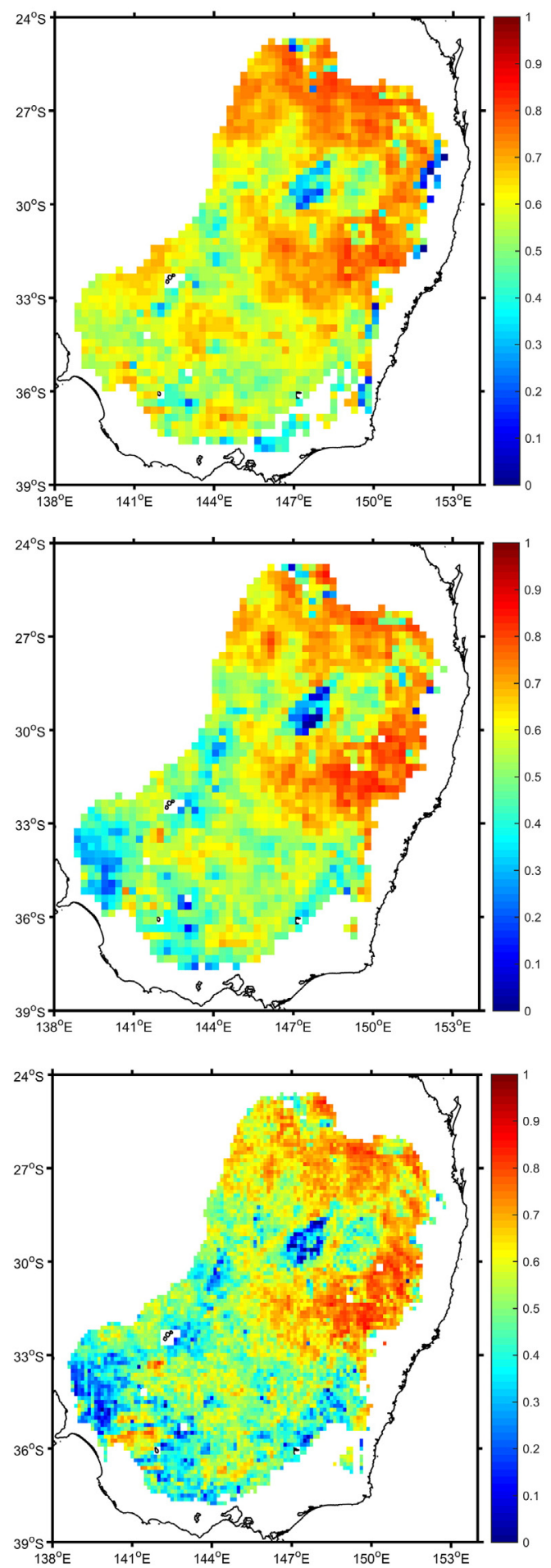

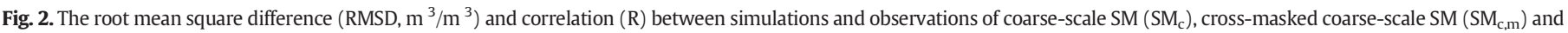
fine-scale $\mathrm{SM}\left(\mathrm{SM}_{\mathrm{f}}\right)$.

Fig. 3 analogously compares the ascending TB simulations at $17.5^{\circ}$ and $52.5^{\circ}$. The RMSD ranged between close to 0 and $30 \mathrm{~K}$, with relatively higher values for H-polarization. Furthermore, the RMSD slightly increased with incidence angle in case of $\mathrm{H}$-polarization, whereas the opposite is true for V-polarization, as was previously observed in (Lievens et al., 2015a). The TB time series were generally characterized by higher correlations as compared to SM, which may partly be due to the more expressed seasonality of $\mathrm{TB}$, dominated by temperature and vegetation variations. In line with the RMSD, higher correlations were obtained for lower angles at $\mathrm{H}$-polarization and higher angles at V-polarization. Generally, similar spatial patterns were observed for the SM and TB metrics.

\subsection{Soil moisture analysis}

The assimilation of various SMOS products was examined (Section 2.2), including: (1) level 3 coarse-scale soil moisture $\left(\mathrm{SM}_{\mathrm{c}}\right)$, 
$\operatorname{RMSD}(\mathrm{K})$

$\mathrm{TB}_{22.5^{\circ}, \mathrm{H}}$

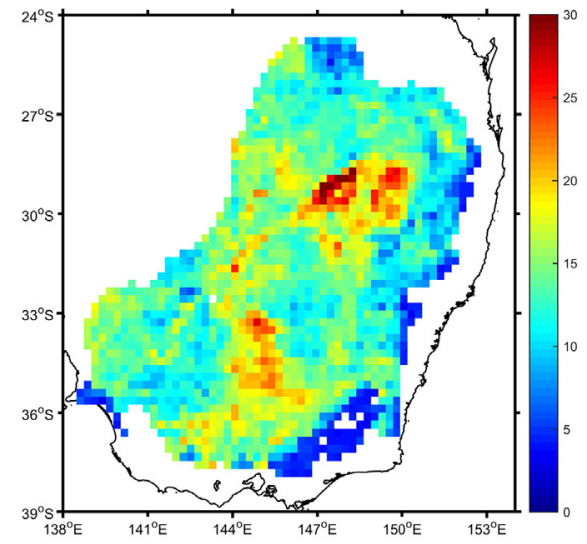

$\mathrm{TB}_{52.5^{\circ}, \mathrm{H}}$

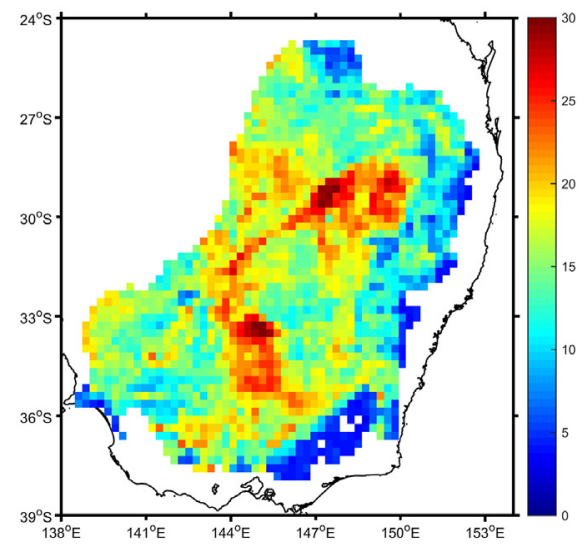

$\mathrm{TB}_{22.5^{\circ}, \mathrm{V}}$

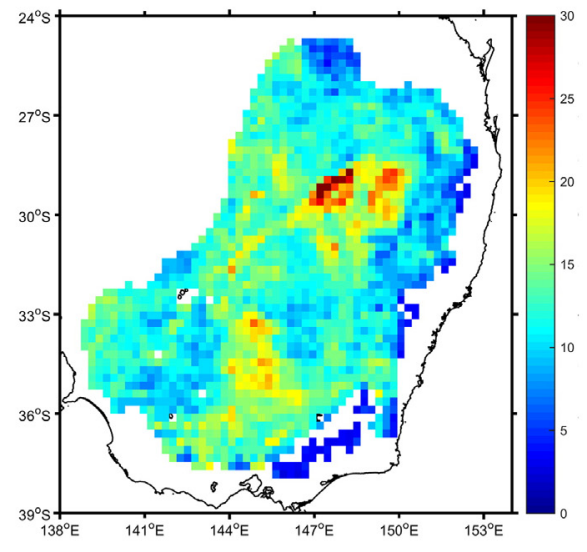

$\mathrm{TB}_{52.5^{\circ}, \mathrm{V}}$

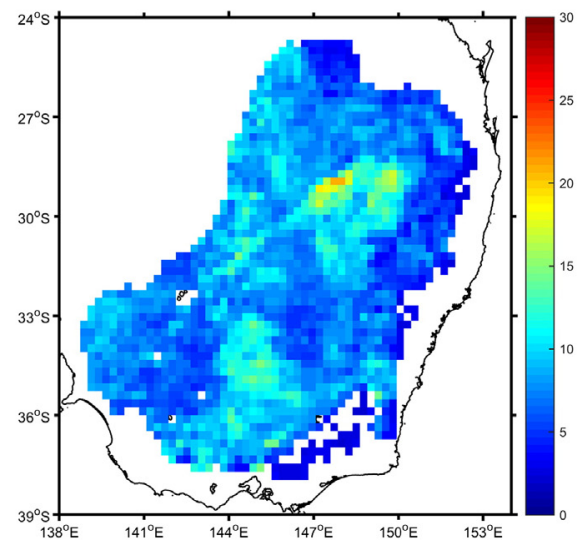

R (-)
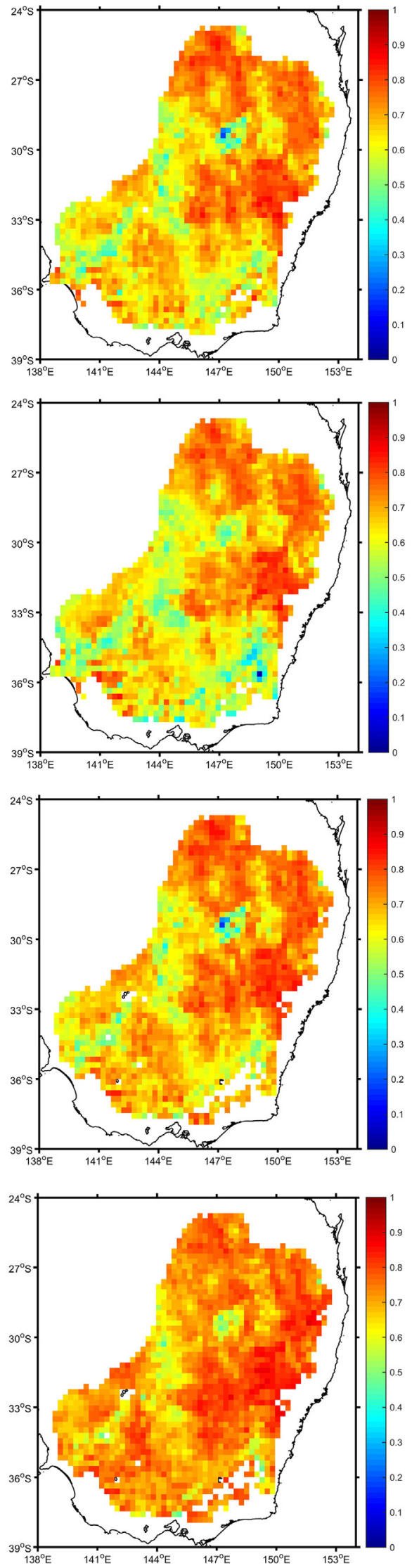

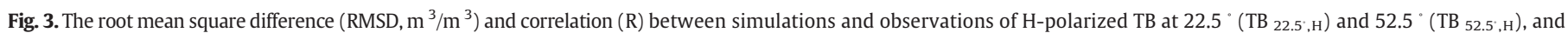

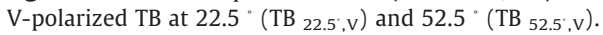


(2) level 4 fine-scale soil moisture $\left(\mathrm{SM}_{\mathrm{f}}\right)$, (3) cross-masked coarse-scale soil moisture $\left(\mathrm{SM}_{\mathrm{c}, \mathrm{m}}\right),(4) \mathrm{H}$-polarized brightness temperatures at approximately $42.5^{\circ}$ incidence angle (TB $\left.{ }_{42.5^{\circ}, \mathrm{H}}\right),(5) \mathrm{H}$ - and V-polarized brightness temperature at $42.5^{\circ}$ incidence angle (TB $\left.42.5^{\circ}, \mathrm{HV}\right)$, and (6) $\mathrm{H}$ - and $\mathrm{V}$-polarized brightness temperatures at a range $\left(17.5-52.5^{\circ}\right)$ of incidence angles (TB $\left.{ }_{\Theta, \mathrm{HV}}\right)$. The DA improvements were assessed by comparing the simulations to hourly in situ soil moisture observations from OzNet, available for 21 model grid cells. The performance was expressed by the bias (simulations or SMOS observations minus in situ measurements, $\mathrm{m}^{3} / \mathrm{m}^{3}$ ), the correlation coefficient ( $R$ ), the root mean square difference (RMSD, $\mathrm{m}^{3} / \mathrm{m}^{3}$ ) and the assimilation efficiency (EFF, \%) (Aubert, Loumagne, and Oudin, 2003), (Brocca et al., 2010), (Brocca et al., 2012):

$\mathrm{EFF}=100\left[1-\frac{\sum_{k}\left(X_{\mathrm{sim}_{\mathrm{DA}}}(k)-X_{\mathrm{obs}}(k)\right)^{2}}{\sum_{k}\left(X_{\mathrm{sim}_{\mathrm{oL}}}(k)-X_{\mathrm{obs}}(k)\right)^{2}}\right]$,

where $k$ is the time, $X_{\mathrm{obs}}$ the observed quantity, and $X_{\mathrm{sim}}{ }_{\mathrm{OL}}$ and $X_{\mathrm{sim}_{\mathrm{DA}}}$ the simulated quantities without (open loop, OL) and with DA, respectively. Efficiencies larger than zero signify the assimilation is improving the model performance; a value of 100 implies a perfect prediction. It is important to note that the validation with point-scale in situ measurements assumes that the latter are representative of the coarser-scale model grid cells, which is an invalid assumption. Hence, the results should be interpreted with caution. To partly decrease the impact of differences in representativeness, the validation metrics (except the bias) were calculated after the simulations were rescaled to the climatology of the in situ measurements through CDF-matching. As a consequence of this rescaling, the validation focuses on relative rather than absolute differences in soil moisture. Finally, the $95 \%$ confidence intervals (CI) for the different metrics were calculated and averaged across the assimilation experiments as in (De Lannoy \& Reichle, in review). The Cls account for the temporal autocorrelation in the soil moisture time series by reducing the degrees of freedom (effective sample size). Nevertheless, the CIs are only indicative, because the spatial autocorrelation between the sites is not accounted for, and the statistical distributions (i.e. $\chi^{2}$ ) associated with the statistical tests for the metrics are only an approximation of the true distributions.

Table 2 lists the performance metrics for the different experiments, averaged over the 21 validation cells. First, it compares the level 3 SMOS soil moisture retrievals to the in situ measurements. Note that for comparison to SMOS the hourly in situ data were cross-masked with the retrievals, decreasing the average number of data points per validation grid cell $n$ to 369 instead of 10,604 for the 2010-2011 period. Notwithstanding a small dry bias $\left(-0.019 \mathrm{~m}^{3} / \mathrm{m}^{3}\right)$, the retrievals showed a strong correspondence with the in situ measurements, as indicated by the high correlation (0.726) and low RMSD $\left(0.045 \mathrm{~m}^{3} / \mathrm{m}^{3}\right)$. Compared to the SMOS retrievals, the VIC open loop simulations showed a lower correspondence with the in situ data, characterized

Table 2

The performance metrics, i.e. bias $\left(\mathrm{m}^{3} / \mathrm{m}^{3}\right)$, correlation (R), root mean square difference (RMSD, $\mathrm{m}^{3} / \mathrm{m}^{3}$ ), and efficiency (EFF, \%), for the hourly soil moisture simulations in comparison to in situ measurements of OzNet, averaged over all 21 model grid cells, for the period of 2010-2011. $n$ denotes the average number of data pairs in the time series records

\begin{tabular}{lrllll}
\hline SM record & $n$ & \multicolumn{1}{l}{ Bias } & R & RMSD & EFF \\
\hline SMOS & 369 & -0.019 & 0.726 & 0.045 & - \\
Open loop & 10,604 & -0.027 & 0.564 & 0.058 & 0 \\
DA-SM $_{\mathrm{c}}$ & 10,604 & -0.031 & 0.690 & 0.049 & 27.4 \\
DA-SM $_{\mathrm{c}, \mathrm{m}}$ & 10,604 & -0.031 & 0.643 & 0.052 & 17.1 \\
DA-SM $_{\mathrm{f}}$ & 10,604 & -0.032 & 0.647 & 0.052 & 17.9 \\
DA-TB $_{42.5, \mathrm{H}}$ & 10,604 & -0.037 & 0.677 & 0.049 & 24.5 \\
DA-TB $_{42.5, \mathrm{HV}}$ & 10,604 & -0.036 & 0.667 & 0.050 & 22.8 \\
DA-TB \\
$\Theta, \mathrm{HV}$ & 10,604 & -0.030 & 0.628 & 0.053 & 14.1 \\
CI & & 0.003 & 0.039 & 0.003 & 1.1 \\
\hline
\end{tabular}

by a bias of $-0.027 \mathrm{~m}^{3} / \mathrm{m}^{3}$, a correlation of 0.564 and RMSD of $0.058 \mathrm{~m}^{3} / \mathrm{m}^{3}$

As revealed by Table 2 , the different assimilation experiments all significantly improved the predictive skill of the model, except for the bias (see discussion below). Furthermore, the impact clearly depended on the observation data set. Thereby, the $\mathrm{SM}_{\mathrm{c}}$ configuration showed the best performance, as indicated by the largest EFF (27.4\%). Use of the downscaled data $\left(\mathrm{SM}_{\mathrm{f}}\right)$ was less efficient (17.9\%). The crossmasking of the coarse-scale retrievals $\mathrm{SM}_{\mathrm{c}, \mathrm{m}}$ led to a similar performance compared to $\mathrm{SM}_{\mathrm{f}}$. The assimilation of $\mathrm{TB}$, with an EFF up to $24.5 \%$, approached the accuracy of the coarse-scale assimilation, particularly if a single configuration (H-polarization and $42.5^{\circ}$ angle) was used. The performance slightly decreased with the inclusion of Vpolarized observations ( $E F F=22.8 \%$ ), and substantially decreased with the multi-angular configuration $(\mathrm{EFF}=14.1 \%)$.

Fig. 4 displays the efficiency of the assimilation experiments in a spatial context over the Murrumbidgee basin. For most configurations, the EFF tended to be lower for the stations in the east of the basin. This may be explained by the relatively higher elevation and dominant forest cover in this area, which are known to decrease the accuracy of SMOS retrievals. The largest EFF was observed for the stations located in the central cropland areas. A distinct behavior was noticeable for $\mathrm{SM}_{\mathrm{f}}$, e.g. showing a remarkably larger EFF for the station in the far east of the basin. This may be explained by an improved correspondence with the local surface fields through the downscaling. Nevertheless, other stations, e.g. in the far west, revealed a decrease in performance after downscaling.

\subsection{Streamflow analysis}

Unlike the soil moisture simulations, which were evaluated at the hourly scale, the streamflow simulations were assessed at the daily time scale to comply with the available gauge measurements. The evaluation was based on measurements of 169 gauge stations across the Murray Darling Basin. The calculated performance metrics were the correlation coefficient $(R)$, the normalized root mean square difference (nRMSD), the Nash-Sutcliffe efficiency (NSE) and the assimilation efficiency (EFF), including their respective confidence intervals based on the $\chi^{2}$-distribution. Note that the nRMSD, i.e. the RMSD normalized by the standard deviation of the observations $\left(\sigma_{\text {obs }}\right)$, was used to account for differences between the scales of the sub-basins.

Table 3 summarizes the performances of the OL and DA experiments, averaged over the 169 gauge stations. A moderate performance of the open loop was found in simulating the streamflow behavior over the basin. For a thorough discussion on the performance of the open loop, we refer to (Lievens et al., 2015b). In contrast with the SM analysis, which showed significant improvements for all assimilation experiments, only minor impacts were observed for the streamflow analysis. The EFF ranged between $1.5 \%$ for the assimilation of $\mathrm{SM}_{\mathrm{c}}$ and $-2.7 \%$ for the assimilation of $\mathrm{TB} 42.5, \mathrm{H}$.

Finally, Fig. 5 shows the spatial distribution of EFF for the assimilation of $\mathrm{SM}_{\mathrm{c}}$ over the Murray Darling Basin. An EFF up to 40\% was still reached for some of the stations. However, a large number of stations revealed EFF-values close to zero, or even negative values down to $-30 \%$. Hence, largely different results were obtained depending on the station. However, there was no clear spatial clustering of the results, indicating that assimilation impacts were not clearly linked to regional conditions, such as land cover or basin characteristics.

\section{Discussion}

The experiments indicated that the assimilation system was best designed to use $\mathrm{SM}_{\mathrm{c}}$ observations. The assimilation of $\mathrm{SM}_{\mathrm{c}}$ clearly improved the predictive skill of the soil moisture simulations, whereas minor improvements could be observed for the streamflow simulations of several stations. As explained in (Lievens et al., 2015b), the impact on 


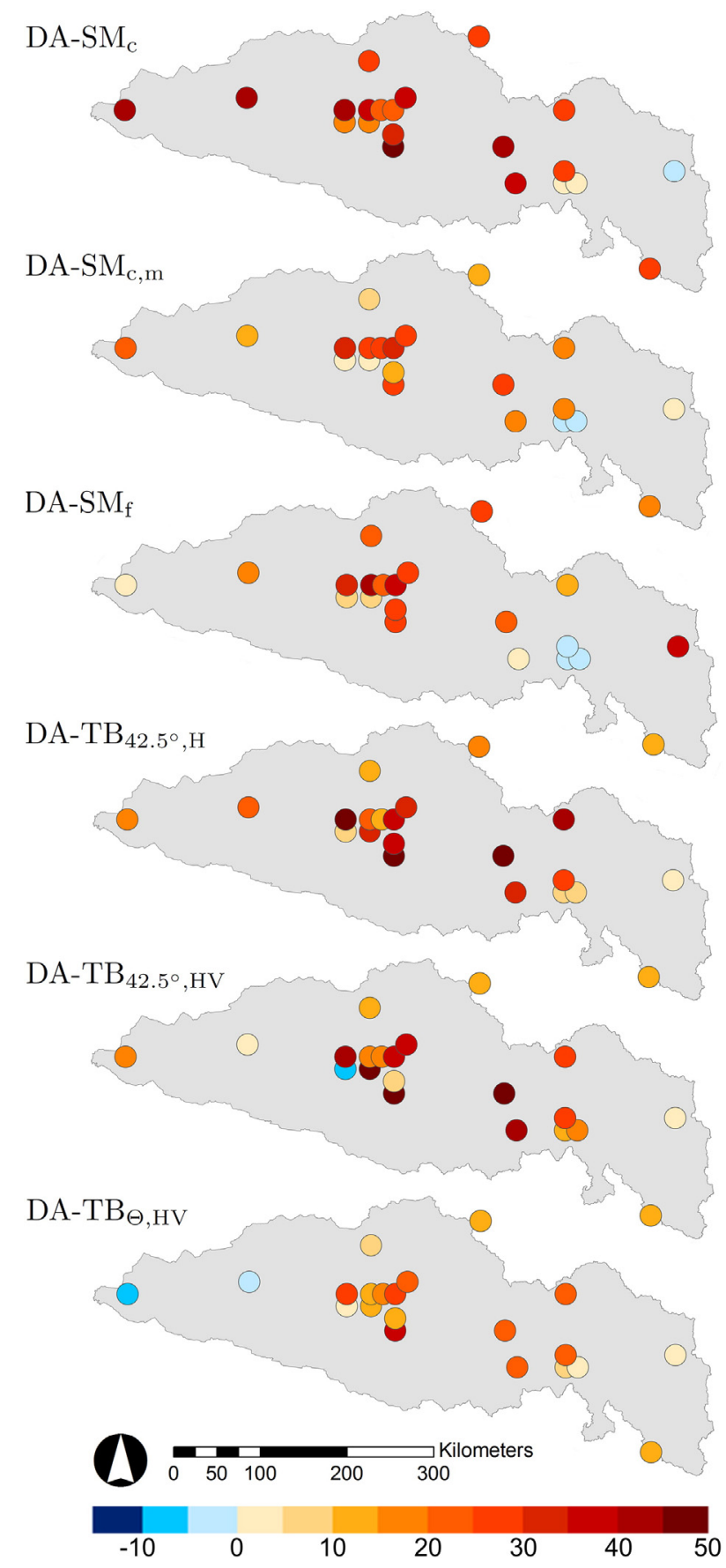

Fig. 4. The spatial distribution of the assimilation efficiency (EFF, \%) over the 21 soil moisture validation grid cells in the Murrumbidgee sub-basin for the different assimilation scenarios.

streamflow simulation may only be minor, partly due to the biascorrection of the assimilated observations through CDF-matching. The latter adequately restricts the impact of the assimilation to the correction of random errors in the soil moisture simulations. However, the impact of these random corrections on the simulated streamflow volume may be very limited, particularly when the threshold soil moisture level to start runoff generation is either not reached or sufficiently exceeded. Therefore, the streamflow simulations may generally show a larger sensitivity to precipitation than to antecedent soil moisture conditions. The relatively lower impact on streamflow simulations may also be attributed to the location of the stream gauge stations. Unlike the soil moisture stations, a vast amount of stream gauge stations is located in the eastern part of the basin, dominated by forest areas and
Table 3

The performance metrics, i.e. correlation (R), normalized root mean square difference (nRMSD), Nash-Sutcliffe efficiency (NSE), and efficiency (EFF, \%), for the daily streamflow simulations in comparison to gauge measurements, averaged over all 169 stations, for the period of 2010-2011. $n$ denotes the average number of data pairs in the time series records.

\begin{tabular}{|c|c|c|c|c|c|}
\hline Streamflow record & $n$ & $\mathrm{R}$ & nRMSD & NSE & $\mathrm{EFF}$ \\
\hline Open loop & 568 & 0.607 & 0.813 & 0.292 & 0 \\
\hline $\mathrm{DA}-\mathrm{SM}_{\mathrm{C}}$ & 568 & 0.625 & 0.801 & 0.305 & 1.5 \\
\hline $\mathrm{DA}-\mathrm{SM}_{\mathrm{c}, \mathrm{m}}$ & 568 & 0.613 & 0.810 & 0.296 & 0.5 \\
\hline $\mathrm{DA}-\mathrm{SM}_{\mathrm{f}}$ & 568 & 0.615 & 0.810 & 0.290 & 0.0 \\
\hline DA-TB ${ }_{42.5, \mathrm{H}}$ & 568 & 0.588 & 0.825 & 0.273 & -2.7 \\
\hline DA-TB $42.5, \mathrm{HV}$ & 568 & 0.597 & 0.820 & 0.277 & -1.9 \\
\hline $\mathrm{DA}-\mathrm{TB}{ }_{\Theta, \mathrm{HV}}$ & 568 & 0.607 & 0.814 & 0.289 & -0.7 \\
\hline $\mathrm{Cl}$ & & 0.006 & 0.007 & 0.003 & 0.04 \\
\hline
\end{tabular}

mountainous areas of the Great Dividing Range. In these areas, SMOS observations are more uncertain and often screened out due to frozen soil or snow conditions, limiting their impact in data assimilation experiments. Given the different station locations and associated conditions, care should be taken when directly comparing the impacts of the assimilation at soil moisture and streamflow levels.

The assimilation of $\mathrm{SM}_{\mathrm{f}}$ showed less encouraging results. This is likely not related to the quality of the soil moisture product, as (Merlin et al., 2012) and (Malbéteau et al., in review) have shown the better agreement of the downscaled data as opposed to the coarsescale retrievals with respect to in situ measurements over Australia. Instead, the decreased assimilation performance may be related to the sparser observations during cloudy conditions. While the average number of observations for 2010-2011 over the 21 validation cells equaled 369 for the coarse-scale data, only 188 observations ( $50 \%)$ were provided in the downscaled data. Hence, the model system received less corrections to missed forcing events. This was demonstrated by the comparison with $\mathrm{SM}_{\mathrm{c}, \mathrm{m}}$. The assimilation of coarse-scale observations, cross-masked with the $\mathrm{SM}_{\mathrm{f}}$ data, also decreased the performance of the simulations compared to the $\mathrm{SM}_{c}$ assimilation. Note that the impact of data gaps induced by cloud cover may be particularly relevant for

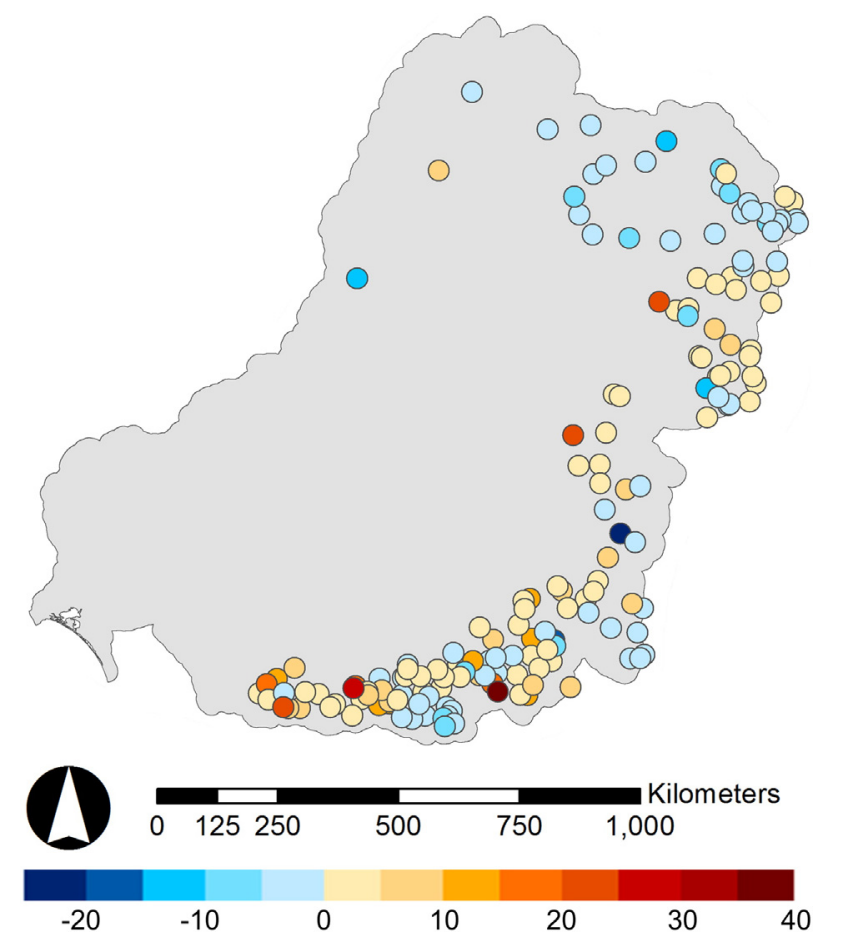

Fig. 5. The spatial distribution of the assimilation efficiency (EFF, \%) over the 169 stream gauge stations in the Murray Darling Basin for the coarse-scale soil moisture $\left(\mathrm{SM}_{\mathrm{c}}\right)$ assimilation scenario. 
hydrologic applications since cloud formation is generally associated with precipitation events. In this context, it is worth mentioning that new downscaling approaches circumventing issues with cloud cover are currently being developed (Piles, Pou, Camps, and Vall-llossera, 2015). Another limitation of the downscaling algorithm is the decrease in performance under atmospheric conditions with lower evaporative demand (Malbéteau et al., in review).

The assimilation of TB at H-polarization and $42.5^{\circ}$ (TB $42.5^{\circ}, \mathrm{H}$ ) improved the $\mathrm{SM}$ simulations in a similar way as $\mathrm{SM}_{\mathrm{c}}$, with only a minor decrease in efficiency (from 27.4 to $24.5 \%$ ). However, the TB assimilation introduced a larger dry bias in the model forecasts, as shown in Table 2 . This may possibly be caused by the simultaneous updating of the soil moisture and temperature profiles. More specifically, a TB observation which is relatively cooler than the a priori forecast simulation can increase the posterior SM forecast, while reducing the soil temperature forecast state. The lower soil temperature could result in a lower sensible heat flux, through which more energy can be transferred to the latent heat flux, i.e. evaporation. As such, the temperature update may have a negative feedback on the updating of SM, as water is more rapidly lost by evaporation. This may be particularly true under semiarid conditions. As a result, there may be a shorter memory associated with updates towards wet conditions, losing water more quickly through evaporation, which can introduce dry bias in the forecast simulations. While the impact of the dry bias was found to be limited with respect to the performance of the SM simulations, it may potentially reduce the predictive skill of the associated streamflow simulations. As shown in Table 3, the TB $42.5^{\circ}, \mathrm{H}$ assimilation decreased the performance with regard to the open loop, with an efficiency of $-2.7 \%$.

Assimilating additional V-polarized and multi-angular TB observations did not improve the soil moisture simulations. On the contrary, a slight decrease in predictive skill was observed for TB ${ }_{42.5^{\circ}, \mathrm{HV}}(\mathrm{EFF}=$ $22.8 \%$ ), whereas a large decrease was found for $\mathrm{TB}_{\Theta, \mathrm{HV}}(\mathrm{EFF}=14.1 \%)$. The main reason is likely due to contradictory innovations. For a given time step, specific sub-sets of polarizations and angles may correspond with positive innovations, whereas others may show negative innovations. This is supported by Fig. 6 , showing the fractional reduction (in $\%$ ) of the mean absolute difference (MAD) between TB observations and simulations for $\mathrm{TB}_{\Theta}{ }_{\Theta} \mathrm{HV}$ versus the MAD between TB observations and simulations for $\mathrm{TB} 42.5^{\circ}, \mathrm{H}$. The MAD, which can be seen as a proxy of the mean absolute innovation, reduced by $10-50 \%$ when calculated

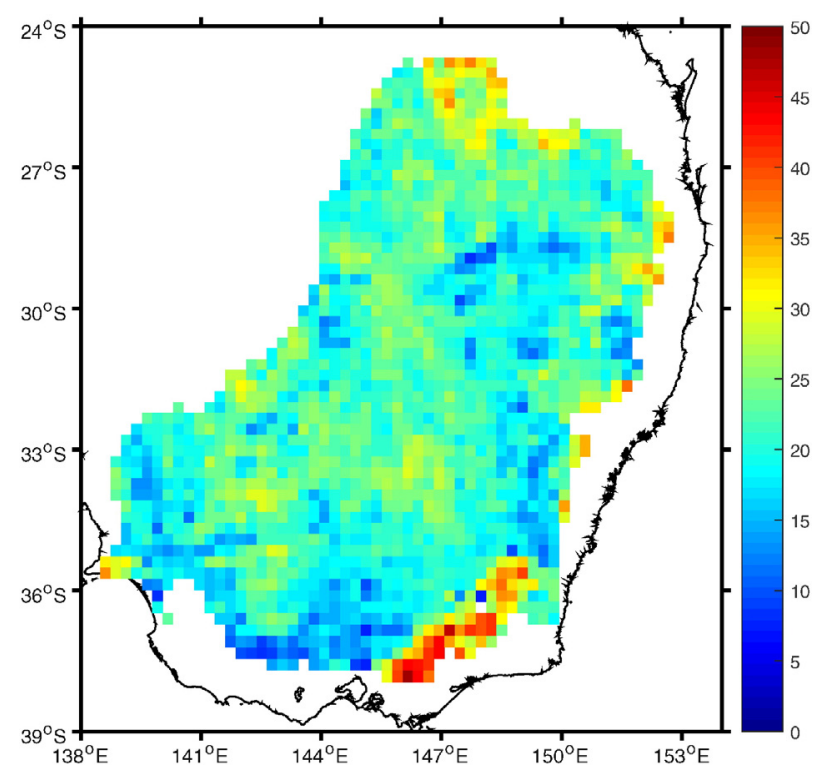

Fig. 6. The reduction (\%) in mean absolute difference (MAD) between simulations and observations of $\mathrm{TB}$ for the multi-angular/polarization configuration $\left(\mathrm{TB}_{\Theta, \mathrm{HV}}\right)$ relative to the

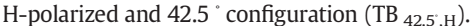

for the multi-angular/polarization configuration. The reduced innovation obviously decreased the impact of the assimilation. Several other aspects may have further contributed to the decreased performance of $\mathrm{TB}_{\Theta, \mathrm{HV}}$. First, the TB observations were strongly correlated between angles and polarizations (e.g. $\mathrm{R}>0.9$ between time series of $\mathrm{TB}{ }_{17.5^{\circ}, \mathrm{H}}$ and $\mathrm{TB}_{52.5^{\circ} \mathrm{v}}$ ). Hence, adding polarizations and angles does not add much information to the system. Second, the number of observations decreased for outer angles, reducing the number of updates accordingly. While the basin-averaged number of observations over the 2010-2011 time period equaled 305 for $42.5^{\circ}$, it reduced to 105 for $17.5^{\circ}$, and 164 for $52.5^{\circ}$. Finally, the SM-TB sensitivity decreases for larger incidence angles due to a lower vegetation transmissivity, which may decrease the usefulness of this data.

Finally, the different performances of the SM and TB configurations may be affected by the vegetation characterization. More specifically, the model framework used climatological LAI, meaning that the same monthly LAI values were used over consecutive years. If the vegetation was relatively better developed for a specific month or year, the use of climatological LAI may have caused a bias in TB. Such biases are partly mitigated in the assimilation of SM, as the retrieval approach for SMOS simultaneously optimizes SM and vegetation optical depth in the cost function (Kerr et al., 2012). Furthermore, different performances may be due to unbalanced model and observation errors for SM and TB assimilation, respectively. The observation error quantification, in particular for TB, could be improved for instance by optimizing angle-dependent errors and by accounting for error correlations between the multi-angular/polarization observations. Differences in assimilation performances may also be introduced through the biascorrection. The bias-correction of TB is more expensive compared to $\mathrm{SM}$, given the contributions of soil moisture, temperature and vegetation to daily, seasonal and inter-annual variability. The larger variability may decrease the usefulness of the CDF-matching approach applied in this study, and may require for a specific bias-correction at the anomaly level. However, an appropriate characterization or subtraction of the TB seasonality would require the assembly of longer data records. Finally, given the large number of aspects that influence the results of an assimilation system, the performance comparison in this study between systems that use different observation products should be considered with care. A different performance may be assessed after the advanced optimization of a specific system.

\section{Conclusions}

This study investigated the potential of assimilating SMOS observations to improve hydrologic simulations by VIC. The assimilated observations distinguished between soil moisture retrievals, either coarse-scaled or downscaled, and brightness temperatures, either in multi-angular/polarization configuration or sub-set configuration. The improvements were assessed by comparison to a large amount of in situ data. Simulations of hourly soil moisture content were validated with measurements of 49 stations (distributed over 21 model grid cells) within the OzNet in situ network in the Murrumbidgee subbasin, whereas daily simulations of streamflow were validated with measurements of 169 gauge stations across the Murray Darling Basin.

With regard to soil moisture simulation, each observation type improved the predictive skill after assimilation. The largest improvements were observed with coarse-scale soil moisture data. The a priori downscaling of SM to the model resolution based on thermal MODIS data was not beneficial to the assimilation. Hampered by cloud cover, the downscaled data had a large number of gaps which reduced the assimilation efficiency. Brightness temperature assimilation showed to be mainly favorable when restricted to the single $42.5^{\circ}$-incidence angle and $\mathrm{H}$ polarization. For this specific configuration, improvements approached those of the coarse-scale SM assimilation. However, a small dry bias in soil moisture was introduced that could mainly be related to feedbacks of the associated soil temperature updates. Adding V-polarized and 
multi-angular data to the TB observation matrix caused dissension in the form of opposing innovations, and consequently narrowed the assimilation results to the open loop.

The improvements in streamflow prediction were less obviously marked. Whereas a minor positive impact was still observed for soil moisture assimilation, the use of brightness temperatures slightly decreased the overall performance of the simulations. The limited impact of the soil moisture assimilation may be attributed to the biascorrection through CDF-matching, limiting the assimilation to correct for random errors only. The correction of random soil moisture errors may not always translate to commensurate corrections in streamflow simulation, as streamflow only shows a clear sensitivity to antecedent soil moisture conditions in the proximity of the threshold to initiate runoff generation. For other conditions, streamflow simulations are mainly sensitive to precipitation. As argued previously, the decrease in performance associated with the TB assimilation may be caused by the increased dry model bias.

Finally, it should be remarked that the optimality of the assimilation scenarios depends to a large extent on the characterization of the model and observation errors, and the selected method for bias-correction. Both aspects clearly require further research. The model and observation errors used in this study were not specifically optimized with respect to performance of each of the assimilation scenarios. Instead, the error contributions were estimated and balanced based on physical approximations. Therefore, a different evaluation could be obtained after rigorous optimization. The bias-correction of TB may require more elaborated methods which account for the increased variability over time due to contributions of temperature and vegetation, verified over longer data records. In this context, a major science challenge lies in the development of techniques that mitigate biases in TB while procuring unbiased estimates of soil moisture and associated water fluxes.

\section{Acknowledgment}

The work has been performed in the framework of the ESA-STSE project 'SMOS + Hydrology Study' and was partly funded through project SR/00/302 ('Hydras +') financed by the Belgian Science Policy (BELSPO), and the CNES Terre, Océan, Surfaces Continentales, Atmosphère (TOSCA) programme. We would like to acknowledge the Australian Bureau of Meteorology for the provision of the streamflow data and the Jülich Supercomputing Center for granting computation time on JUROPA. Hans Lievens is a postdoctoral research fellow of the Research Foundation Flanders (FWO). Valentijn Pauwels is currently a Future Fellow funded by the Australian Research Council.

\section{References}

Al Bitar, A., Leroux, D., Kerr, Y. H., Merlin, O., Richaume, P., Sahoo, A., \& Wood, E. F. (2012). Evaluation of SMOS soil moisture products over continental US using the SCAN/ SNOTEL network. IEEE Transactions on Geoscience and Remote Sensing, 50, 1572-1586.

Al-Yaari, A., Wigneron, J. P., Ducharne, A., Kerr, Y. H., De Rosnay, P., de Jeu, R., ... Mialon, A. (2014a). Global-scale evaluation of two satellite-based passive microwave soil moisture datasets (SMOS and AMSR-E) with respect to Land Data Assimilation System estimates. Remote Sensing of Environment, 149, 181-195.

Al-Yaari, A., Wigneron, J. P., Ducharne, A., Kerr, Y. H., Wagner, W., De Lannoy, G., ... Mialon, A. (2014b). Global-scale comparison of passive (SMOS) and active (ASCAT) satellite based microwave soil moisture retrievals with soil moisture simulations (MERRALand). Remote Sensing of Environment, 152, 614-626. http://dx.doi.org/10.1016/j.rse. 2014.07.013.

Albergel, C., de Rosnay, P., Gruhier, C., Sabater, J. M., Hasenauer, S., Isaksen, L., ... Wagner, W. (2012). Evaluation of remotely sensed and modelled soil moisture products using global ground-based in situ observations. Remote Sensing of Environment, 118, 215-226.

Aubert, D., Loumagne, C., \& Oudin, L. (2003). Sequential assimilation of soil moisture and streamflow data in a conceptual rainfall runoff model. Journal of Hydrology, 280, $145-161$.

Balsamo, G., Mahfouf, J. -F., Belair, S., \& Deblonde, G. (2006). A global root-zone soil moisture analysis using simulated L-band brightness temperature in preparation for the HYDROS satellite mission. Journal of Hydrometeorology, 7, 1126-1146.
Brocca, L., Melone, F., Moramarco, T., Wagner, W., Naeimi, V., Bartalis, Z., \& Hasenauer, S. (2010). Improving runoff prediction through the assimilation of the ASCAT soil moisture product. Hydrology and Earth System Sciences, 14, 1881-1893.

Brocca, L., Moramarco, T., Melone, F., Wagner, W., Hasenauer, S., \& Hahn, S. (2012). Assimilation of surface- and root-zone ASCAT soil moisture products into rainfall-runoff modeling. IEEE Transactions on Geoscience and Remote Sensing, 50, 2542-2555.

Brooks, R. H., \& Corey, A. T. (1964). Hydraulic properties of porous media. Hydrology papers. 3. (pp. 1-37). Colorado State University.

Crow, W. T., Koster, R., Reichle, R., \& Sharif, H. (2005). Relevance of time-varying and time-invariant retrieval error sources on the utility of spaceborne soil moisture products. Geophysical Research Letters, 32, L24405.

De Lannoy, G. J. M., \& Reichle, R. (2015). Global Assimilation of Multi-angle and Multipolarization SMOS Brightness Temperature Observations into the GEOS-5 Catchment Land Surface Model for Soil Moisture Estimation. J. Hydrometeorol in review.

De Lannoy, G. J. M., Reichle, R. Houser, P. R. Arsenault, K. R. Verhoest, N. E. C., \& Pauwels, V. R. N. (2010). Satellite-scale snow water equivalent assimilation into a highresolution land surface model. Journal of Hydrometeorology, 11, 352-369.

De Lannoy, G. J. M., Reichle, R. H., \& Pauwels, V. R. N. (2013). Global calibration of the GEOS-5 L-band microwave radiative transfer model over nonfrozen land using SMOS observations. Journal of Hydrometeorology, 14, 765-785.

de Rosnay, P., Drusch, M., Boone, A., Balsamo, G., Decharme, B., Harris, P., ... Wigneron, J. -P. (2009). AMMA land surface model intercomparison experiment coupled to the Community Microwave Emission Model: ALMIP-MEM. Journal of Geophysical ResearchAtmospheres, 114, D05108.

Dickinson, R. E., Henderson-Sellers, A., Kennedy, P. J., \& Wilson, M. F. (1986). Biosphereatmosphere transfer scheme (BATS) for the NCAR community climate model. typeTechnical Report NumberTN-275 + STR

Djamai, N., Magagi, R., Goita, K., Hosseini, M., Cosh, M. H., Berg, A., \& Toth, B. (2015). Evaluation of SMOS soil moisture products over the CanEx-SM10 area. Journal of Hydrology, 520, 254-267.

Drusch, M., Holmes, T., de Rosnay, P., \& Balsamo, G. (2009). Comparing ERA-40-based Lband brightness temperatures with Skylab observations: A calibration/validation study using the Community Microwave Emission Model. Journal of Hydrometeorology, $10,213-226$.

Dumedah, G., \& Walker, J. P. (2014). Intercomparison of the JULES and CABLE land surface models through assimilation of remotely sensed soil moisture in southeast Australia. Advances in Water Resources, 74, 231-244.

Escorihuela, M. J., Chanzy, A., Wigneron, J. P., \& Kerr, Y. H. (2010). Effective soil moisture sampling depth of L-band radiometry: A case study. Remote Sensing of Environment 114, 995-1001.

Evensen, G. (1994). Sequential data assimilation with a nonlinear quasi-geostrophic model using Monte Carlo methods to forecast error statistics. Journal of Geophysical Research, Oceans, 99, 10143-10162.

Han, X., Hendricks-Franssen, H. -J., Li, X., Zhang, Y., Montzka, C., \& Vereecken, H. (2013). Joint assimilation of surface temperature and L-band microwave brightness temperature in land data assimilation. Vadose Zone Journal, 12

Han, X., Hendricks Franssen, H. -J., Montzka, C., \& Vereecken, H. (2014). Soil moisture and soil properties estimation in the Community Land Model with synthetic brightness temperature observations. Water Resources Research, 50, 6081-6105.

Hansen, M., Defries, R., Townshend, J., \& Sohlberg, R. (2000). Global land cover classification at $1 \mathrm{~km}$ spatial resolution using a classification tree approach. International Journal of Remote Sensing, 21, 1331-1364.

Holmes, T. R. H., Drusch, M., Wigneron, J. -P., \& de Jeu, R. A. M. (2008). A global simulation of microwave emission: Error structures based on output from ECMWF's operational integrated forecast system. IEEE Transactions on Geoscience and Remote Sensing, 46 $846-856$.

Jackson, T. J., Bindlish, R., Cosh, M. H., Zhao, T., Starks, P. J., Bosch, D. D. ... Leroux, D. (2012) Validation of Soil Moisture and Ocean Salinity (SMOS) soil moisture over watershed networks in the U.S. IEEE Transactions on Geoscience and Remote Sensing, 50 $1530-1543$.

Jackson, T. J., Schmugge, T. J., \& Wang, J. R. (1982). Passive microwave remote sensing of soil moisture under vegetation canopies. Water Resources Research, 18, 1137-1142.

Jacquette, E., Al Bitar, A., Mialon, A., Kerr, Y., Quesney, A., Cabot, F., \& Richaume, P. (2010) SMOS CATDS level 3 global products over land. In C. M. U. Neale, \& A. Maltese (Eds.), BooktitleRemote Sensing for Agriculture, Ecosystems, and Hydrology XII. Volume 7824 of seriesProceedings of SPIE-The International Society for Optical Engineering. Note Conference on Remote Sensing for Agriculture, Ecosystems, and Hydrology XII, Toulouse, France.

Jones, D. A., Wang, W., \& Fawcett, R. (2009). High-quality spatial climate data-sets for Australia. Australian Meteorological and Oceanographic Journal, 58, 233-248.

Kerr, Y. H., Waldteufel, P., Richaume, P., Davenport, I., Ferrazzoli, P., \& Wigneron, J. P. (2011). Algorithm theoretical basis document (ATBD) for the SMOS level 2 soil moisture processor. TypeTechnical Report NumberSO-TN-ESL-SM-GS-0001 SM-ESL (CBSA) AddressToulouse.

Kerr, Y. H., Waldteufel, P., Richaume, P., Wigneron, J. P., Ferrazzoli, P., Mahmoodi, A., Delwart, S. (2012). The SMOS soil moisture retrieval algorithm. IEEE Transactions on Geoscience and Remote Sensing, 50, 1384-1403.

Knyazikhin, Y., Glassy, J., Privette, J. L., Tian, Y., Lotsch, A., Zhang, Y., ... Running, S. W. (1999). MODIS leaf area index (LAI) and fraction of photosynthetically active radiation absorbed by vegetation (FPAR) product (MOD15) algorithm theoretical basis document. TypeTechnical Report.

Kornelsen, K. C., Cosh, M. H., \& Coulibaly, P. (2015). Potential of bias correction for downscaling passive microwave and soil moisture data. Journal of Geophysical Research Atmospheres, 120, 6460-6479.

Kornelsen, K. C., \& Coulibaly, P. (2015). Reducing multiplicative bias of satellite soil moisture retrievals. Remote Sensing of Environment, 165, 109-122. 
Kumar, S. V., Reichle, R. H., Harrison, K. W., Peters-Lidard, C. D., Yatheendradas, S., \& Santanello, J. A. (2012). A comparison of methods for a priori bias correction in soil moisture data assimilation. Water Resources Research, 48, W07523.

Leroux, D. J., Kerr, Y. H., Al Bitar, A., Bindlish, R., Jackson, T. J., Berthelot, B., \& Portet, G. (2014). Comparison between SMOS, VUA, ASCAT, and ECMWF soil moisture products over four watersheds in US. IEEE Transactions on Geoscience and Remote Sensing, 52, 1562-1571.

Leroux, D. J., Kerr, Y. H., Richaume, P., \& Fieuzal, R. (2013). Spatial distribution and possible sources of SMOS errors at the global scale. Remote Sensing of Environment, 133 240-250.

Li, H., Sheffield, J., \& Wood, E. F. (2010). Bias correction of monthly precipitation and temperature fields from Intergovernmental Panel on Climate Change AR4 models using equidistant quantile matching. Journal of Geophysical Research-Atmospheres, 115, D10101.

Liang, X., Lettenmaier, D., Wood, E., \& Burges, S. (1994). A simple hydrologically based model of land-surface water and energy fluxes for general-circulation models. Journal of Geophysical Research-Atmospheres, 99, 14415-14428.

Liang, X., Wood, E., \& Lettenmaier, D. (1996). Surface soil moisture parameterization of the VIC-2 L model: Evaluation and modification. Global and Planetary Change, 13, 195-206.

Liang, X., Wood, E., \& Lettenmaier, D. (1999). Modeling ground heat flux in land surface parameterization schemes. Journal of Geophysical Research-Atmospheres, 104, 9581-9600.

Lievens, H., Al Bitar, A., Verhoest, N. E. C., Cabot, F., De Lannoy, G. J. M., Drusch, M., .. Pauwels, V. R. N. (2015a). Optimization of a radiative transfer forward operator for simulating SMOS brightness temperatures over the Upper Mississippi Basin, USA. Journal of Hydrometeorology, 16, 1109-1134.

Lievens, H., Kumar Tomer, S., Al Bitar, A., De Lannoy, G. J. M., Drusch, M., Dumedah, G., .. Pauwels, V. R. N. (2015b). SMOS soil moisture assimilation for improved hydrologic simulation in the Murray Darling Basin, Australia. Remote Sensing of Environment, 168, 146-162.

Louvet, S., Pellarin, T., Al Bitar, A., Cappelaere, B., Galle, S., Grippa, M., ... De Rosnay, P. (2015). SMOS soil moisture product evaluation over West-Africa from local to regional scale. Remote Sensing of Environment, 156, 383-394.

Malbéteau, Y., Merlin, O., Molero, B., Rüdiger, C., \& Bacon, S. (2015). DisPATCh as a tool for improving validation strategies of coarse-scale remotely sensed soil moisture: Application to SMOS and AMSR-E data in southeastern Australia. International Journal of Applied Earth Observation and Geoinformation in review.

Martens, B., Miralles, D., Lievens, H., Fernández-Prieto, D., \& Verhoest, N. E. C. (2015). Improving terrestrial evaporation estimates over continental Australia through assimilation of SMOS soil moisture. International Journal of Applied Earth Observation and Geoinformation in press.

McKenzie, N. J. Jacquier, D. W. Maschmedt, D. J. Griffin, E. A. \& Brough, D. M. (2012). The Australian soil resource information system (ASRIS) technical specifications. TypeTechnical Report Number Revised Version 1.6 The Australian Collaborative Land Evaluation Program.

Mecklenburg, S., Drusch, M., Kerr, Y. H., Font, J., Martin-Neira, M., Delwart, S., .. Crapolicchio, R. (2012). ESA's Soil Moisture and Ocean Salinity Mission: Mission performance and operations. IEEE Transactions on Geoscience and Remote Sensing, 50, 1354-1366. http://dx.doi.org/10.1109/TGRS.2012.2187666.

Merlin, O., Escorihuela, M. J., Mayoral, M. A., Hagolle, O., Al Bitar, A., \& Kerr, Y. (2013). Selfcalibrated evaporation-based disaggregation of SMOS soil moisture: An evaluation study at $3 \mathrm{~km}$ and $100 \mathrm{~m}$ resolution in Catalunya, Spain. Remote Sensing of Environment, 130, 25-38.

Merlin, O., Rüdiger, C., Al Bitar, A., Richaume, P., Walker, J., \& Kerr, Y. (2012). Disaggregation of smos soil moisture in southeastern Australia. IEEE Transactions on Geoscience and Remote Sensing, 50, 1556-1571.

Pan, M., Sahoo, A. K., Wood, E. F., Al Bitar, A., Leroux, D., \& Kerr, Y. H. (2012). An initial assessment of SMOS derived soil moisture over the continental United States. IEEE Journal of Selected Topics in Applied Earth Observation Remote Sensing, 5, 1448-1457. http://dx.doi.org/10.1109/JSTARS.2012.2194477.

Pauwels, V. R. N., \& De Lannoy, G. J. M. (2009). Ensemble-based assimilation of discharge into rainfall-runoff models: A comparison of approaches to mapping observational information to state space. Water Resources Research, 8, W08428.

Piles, M., Pou, X., Camps, A., \& Vall-llossera, M. (2015). Validation of SMOS-BEC L4 high resolution soil moisture products, version 3.0 or "all-weather". TypeTechnical Report SMOS Barcelona Expert Centre.
Rahmoune, R., Ferrazzoli, P., Singh, Y. K., Kerr, Y. H., Richaume, P., \& Al Bitar, A. (2014). SMOS retrieval results over forests: Comparisons with independent measurements. IEEE Journal of Selected Topics in Applied Earth Observation Remote Sensing, 7, 3858-3866. http://dx.doi.org/10.1109/JSTARS.2014.2321027.

Reichle, R., De Lannoy, G. J. M., Forman, B. A., Draper, C. S., \& Liu, Q (2014). Connecting satellite observatins with water cycle variables through land data assimilation: Examples using the NASA GEOS-5 LDAS. Surveys in Geophysics, 35, 577-606.

Reichle, R., \& Koster, R. D. (2003). Assessing the impact of horizontal error correlations in background fields on soil moisture estimation. Journal of Hydrometeorology, 4, $1229-1242$

Reichle, R., \& Koster, R. D. (2004). Bias reduction in short records of satellite soil moisture. Geophysical Research Letters, 31, L19501.

Reichle, R., Koster, R. D., Dong, J., \& Berg, A. (2004). Global soil moisture from satellite observations, land surface models, and ground data: Implications for data assimilation. Journal of Hydrometeorology, 5, 430-442.

Reichle, R., McLaughlin, D. B., \& Entekhabi, D. (2002). Hydrologic data assimilation with the ensemble Kalman filter. Monthly Weather Review, 120, 103-114.

Ridler, M. -E., Madsen, H., Stisen, S., Bircher, S., \& Fensholt, R. (2014). Assimilation of SMOS-derived soil moisture in a fully integrated hydrological and soil-vegetationatmosphere transfer model in Western Denmark. Water Resources Research, 50, 8962-8981.

Rienecker, M. M., Suarez, M. J. Gelaro, R., Todling R., Bacmeister, J, Liu, E, Bosilovich, M. G. , Schubert, S. D., Takacs, L., Kim, G., Bloom, S., Chen, J., Collins, D., Conaty, A., da Silva, A., et al. (2011). MERRA - NASA's Modern-Era Retrospective Analysis for Research and Applications. Journal of Climate, 24, 3624-3648.

Sahoo, A. K. De Lannoy, G. J. M. Reichle, R. H. \& Houser, P. R. (2013). Assimilation and downscaling of satellite observed soil moisture over the Little River experimental watershed in Georgia, USA. Advances in Water Resources, 52, 19-33.

Smith, A. B., Walker, J. P., Western, A. W., Young, R. I., Ellett, K. M., Pipunic, R. C., ... Richter, H. (2012). The Murrumbidgee soil moisture monitoring network data set. Water Resources Research, 48, W07701.

Su, C. -H., \& Ryu, D. (2015). Multi-scale analysis of bias correction of soil moisture. Hydrology and Earth System Sciences, 19, 17-31.

Su, C. -H., Ryu, D., Crow, W. T., \& Western, A. W. (2014). Beyond triple collocation: Applications to soil moisture monitoring. Journal of Geophysical Research-Atmospheres, 119, 6419-6439.

Su, C. -H., Ryu, D., Young, R. I., Western, A. W., \& Wagner, W. (2013). Inter-comparison of microwave satellite soil moisture retrievals over the Murrumbidgee Basin, southeast Australia. Remote Sensing of Environment, 134, 1-11.

Turner, M. R. J., Walker, J. P., \& Oke, P. R. (2008). Ensemble member generation for sequential data assimilation. Remote Sensing of Environment, 112, 1421-1433.

Verhoest, N. E. C., van den Berg, M. J., Martens, B., Lievens, H., Wood, E. F., Pan, M., ... Pauwels, V. R. N. (2015). Copula-based downscaling of coarse-scale soil moisture observations with implicit bias correction. IEEE Transactions on Geoscience and Remote Sensing, 53, 3507-3521.

Wanders, N., Karssenberg, D., de Roo, A., de Jong, S. M., \& Bierkens, M. F. P. (2014). The suitability of remotely sensed soil moisture for improving operational flood forecasting. Hydrology and Earth System Sciences, 18, 2343-2357.

Wigneron, J. P., Kerr, Y. H., Waldteufel, P., Saleh, K., Escorihuela, M. J., Richaume, P., ... Schwank, M. (2007). L-band Microwave Emission of the Biosphere (L-MEB) model: Description and calibration against experimental data sets over crop fields. Remote Sensing of Environment, 107, 639-655.

Wigneron, J. -P., Schwank, M., Lopez Baeza, E., Kerr, Y., Novello, N., Millan, C., ... Mecklenburg, S. (2012). First evaluation of the simultaneous SMOS and ELBARA-II observations in the Mediterranean region. Remote Sensing of Environment, 124, $26-37$.

Wilker, H., Drusch, M., Seuffert, G., \& Simmer, C. (2006). Effects of the near-surface soil moisture profile on the assimilation of L-band microwave brightness temperature. Journal of Hydrometeorology, 7, 433-442.

Wood, E. F., Roundy, J. K., Troy, T. J., van Beek, L. P. H., Bierkens, M. F. P., Blyth, E., ... Whitehead, P. (2011). Hyperresolution global land surface modeling: Meeting a grand challenge for monitoring earth's terrestrial water. Water Resources Research, 47, W05301.

Yilmaz, M. T., \& Crow, W. T. (2013). The optimality of potential rescaling approaches in land data assimilation. Journal of Hydrometeorology, 14, 650-660.

Zhao, R. -J., Zang, Y. -L., Fang, L. -R., Liu, X. -R., \& Zhang, Q. -S. (1980). The Xinanjiang model. Hydrological Forecasting Proceedings Oxford Symposium, Lash. 129. (pp. 351-356). 